\title{
ESTRATEGIA, OPERACIONES Y LOGÍSTICA EN UN CONFLICTO MEDITERRÁNEO. LA REVUELTA DEL JUEZ DE ARBOREA Y LA "ARMADA E VIATGE" DE PEDRO EL CEREMONIOSO A CERDEÑA (1353-1354)
}

\author{
STRATEGY, OPERATIONS AND LOGISTICS \\ IN A MEDITERRANEAN CONFLICT. \\ THE JUDGE OF ARBOREA'S REBELLION \\ AND PETER THE CEREMONIOUS' "ARMADA E VIATGE" \\ TO SARDINIA (1353-1354)
}

\author{
MARIO ORSI LÁZARO \\ Institución Milá y Fontanals \\ CSIC, Barcelona
}

\begin{abstract}
Resumen: En 1353 el juez de Arborea, el más poderoso aliado y vasallo de Pedro el Ceremonioso en Cerdeña, se rebeló y atacó los territorios regios de la isla, cooperando con rebeldes y enemigos del rey como Génova, Milán y la familia de los Doria. En 1354 Pedro el Ceremonioso, rey de Aragón, comandó una potente armada a la isla tratando de combatir a sus enemigos en su territorio. La campaña de 1354 fue cuidadosamente planeada, pero la resistencia de la ciudad de Alguer detuvo las operaciones de la flota y el ejército regios, poniendo a prueba un sistema logístico incapaz de apoyar una expedición tan grande y falta de suministros. Este trabajo expone cómo las realidades geoestratégicas, políticas, operacionales y logísticas estuvieron estrechamente relacionadas para configurar el perfil de una potente campaña militar, y cómo dichas realidades pueden servir para entender cambios militares, políticos e históricos de mayor alcance y duración.
\end{abstract}

Palabras clave: Corona de Aragón; Historia militar; Guerra medieval; Cerdeña; Estrategia; Logística; Siglo XIV; Pedro el Ceremonioso.

\begin{abstract}
In 1353, the judge of Arborea, the most powerful ally and vassal of king Peter "the Ceremonious" in Sardinia, rose up and attacked the king's territories in the island, cooperating with rebels and enemies of the king, such as Genoa, Milan and the Doria family. In 1354, Peter "the Ceremonious", king of Aragon, led a powerful army to Sardinia, intending to fight his enemies in their territories. The 1354 campaign was carefully planned, but the resistance of the city of Alghero stopped the royal army and fleet operations, challenging a logistical system unable to support such a huge and unsupplied military expedition. This paper demonstrates the way geostrategic, political, operational and logistical realities were closely linked to configure the profile of a powerful military campaign, and how these realities can be useful to understand broader military, political and historical changes.
\end{abstract}

Keywords: Crown of Aragon; Military History; Medieval Warfare; Sardinia; Strategy; Logistics; 14th century; Peter the Ceremonious. 


\section{SUMARIO $^{1}$}

Introducción.- I. Condicionantes para una campaña.- 1. Los precedentes inmediatos: la guerra contra Génova, Alguer y el juez de Arborea.- 2. Condicionantes geográficos. a) El mar: motivación, vía y obstáculo para el control de Cerdeña. b) Cerdeña. Territorio y economía de un escenario de guerra.- 3. Condicionantes políticos y militares: Génova, el señor de Milán y el juez de Arborea. a) Génova: una potencia naval concentrada en Oriente. b) El juez de Arborea. II. Objetivos estratégicos, planificación y desarrollo de las operaciones.- 1. La ofensiva del juez y de sus aliados: Cagliari, Alguer y Sássari.- 2. Buscando una ejecución de justicia definitiva: la expedición regia de 1354.- a) Planes iniciales hacia una victoria decisiva: el intento de combate naval y de ataque a Oristano. b) El reflejo obsidional: el sitio de Alguer.III. La logística.- 1. La alimentación del ejército .- 2. El transporte.- Conclusiones.

\section{INTRODUCCIÓN}

Es bien sabido que la Corona de Aragón, durante la Baja Edad Media, llevó a cabo una considerable expansión comercial y también militar, con desigual participación de sus fuerzas económicas, políticas y sociales en cada una de ellas. A lo largo de dos siglos y medio, los monarcas de la casa de Aragón, secundados con entusiasmo o de mala gana por sus súbditos, desarrollaron ambiciosos proyectos políticos y se vieron envueltos en constantes conflictos, cada vez más alejados de sus centros de poder y de producción, dentro del juego de los grandes poderes occidentales y mediterráneos. Esta proyección estratégica, política a la vez que militar, exigió, por todo ello, la creación y el mantenimiento de ejércitos y flotas capaces de operar en todos los puntos críticos del Mediterráneo, desde el estrecho de Gibraltar hasta el del Bósforo, en teatros de operaciones tan dispares como Sicilia, la Toscana, Túnez o Cerdeña.

Ninguno de estos hechos puede entenderse de forma aislada, sino siempre en el contexto de un proceso de larga duración y de amplio alcance

${ }^{1}$ Este trabajo se inscribe en el marco del proyecto de investigación aprobado y financiado por el Ministerio de Educación y Ciencia titulado "La Corona de Aragón en el Mediterráneo medieval: puente entre culturas, mediadora entre Cristiandad e Islam." (HUM2007-61131) y cuenta igualmente con el respaldo del Comissionat per a Universitats i Recerca del Departament d'Innovació, Universitats i Empresa de la Generalitat de Catalunya y del Fondo Social Europeo. Abreviaturas utilizadas: AHPB $=$ Archivo Histórico de Protocolos de Barcelona; ACB $=$ Archivo de la Catedral de Barcelona; AHCB = Archivo Histórico de la Ciudad de Barcelona; $\mathrm{ACA}=$ Archivo de la Corona de Aragón; $C=$ Cancilleria; $R P=$ Real Patrimonio; $M R=$ Maestre Racional; $C R=$ Cartas Reales; $B G C=$ Bailía General de Cataluña; BRABLB = Boletín de la Real Academia de Buenas Letras de Barcelona; CODOIN = Colección de Documentos Inéditos de la Corona de Aragón; AEM = Anuario de Estudios Medievales; vol = volumen; fol $=$ folio; reg = registro; $\mathrm{c}=$ carta; $\mathrm{r}=$ recto; $\mathrm{v}=$ verso; doc. = documento; cit. = citado. Los precios y salarios se expresan en sueldos de Barcelona, equivaliendo 1 florín a 11 sueldos. Las fuentes cronísticas utilizadas serán abreviadas de la siguiente manera: Pedro IV, Crónica = PERE EL CEREMONIÓS, Crònica, en Ferran SOLDEVILA ZUBIBURU (ed.), Les quatre grans cròniques, Barcelona, Selecta, 1971; R. MUNTANER, Crónica = Ramon MUNTANER, Crònica, en F SOLDEVILA (ed.), Les quatre grans cròniques; JAIME I, Llibre dels feyts = JAUME I, Llibre dels feyts del rey en Jacme, en F. SOLDEVILA (ed.), Les quatre grans cróniques (hay una reciente reedición de esta crónica a cargo de Jordi BRUGUERA y María Terésa FERRER MALLOL, Barcelona, Institut d'Estudis Catalans, 2007); J.ZURITA, Anales = Jerónimo ZURITA, Anales de Aragón, Zaragoza, Institución Fernando el Católico-CSIC, 1973; M. VILLANI, Istorie = Matteo VILLANI, Istorie Fiorentine, en Ludovico Antonio MURATORI (ed.), Rerum Italicarum Scriptores, XIV, Roma, Arnaldo Furni Editore, 1978. 
geográfico, que se dio de forma paralela y constante en todo el occidente europeo a lo largo de varios siglos (XIII-XVIII), extendiéndose a las periferias territoriales y a las fronteras cronológicas de estas acotaciones. El proceso ha sido identificado, haciendo hincapié en sus diversos aspectos ${ }^{2}$, desde varias líneas de pensamiento que tuvieron su embrión en la renovación metodológica que, desde la Europa de entreguerras, llevó a una concepción de la Historia más abierta a las realidades socioeconómicas y al contexto cultural que rodeaban y condicionaban los hechos descritos en las fuentes ${ }^{3}$.

${ }^{2}$ La revolución militar ha sido el paradigma historiográfico de mayor impacto, centrado en buena medida, para la Edad Media, en la Guerra de los Cien Años y en sus principales monarquías contendientes. Hay abundante bibliografía sobre este tema, dedicada a la época modernạ, que se basa en êl análisis de los procesos de construcción del estado moderno desde las innovaciones militares (véase Geoffrey PARKER, La revolución militar. Las innovaciones militares y el apogeo de occidente 1500-1800, Barcelona, Crítica, 1988). También ha habido, sin embargo, aproximaciones en esta línea para la época medieval; véanse Clifford ROGERS, The military Revolutions of the Hundred Years' War, "The Journal of Military History", 57-2 (abril-1993), pp. 241-278 y la respuesta de John STONE, Technology, Society, and the Infantry Revolution of the Fourteenth Century, "The Journal of Military History", 68 (abril-2004), pp. 361-380; Andrew AYTON; James PRICE, The Medieval Military Revolution: State, Society and Military Ćhange in Medieval and Early Modern Europe, Londres, Tauris Academic Studies, 1994.

${ }^{3}$ Tras el final de la última Guerra Mundial, la historia militar se hizo eco de estos cambios, generando una extensa tradición historiográfica que ha enriquecido enormemente la comprensión del fenómeno militar como elemento intrínseco a la sociedad que lo produce. Las renovaciones metodológicas experimentadas por la historia militar en la segunda mitad del siglo XX tomaron (y siguen) distintos caminos. Sin ánimo de resumir aquí una temática tan amplia, cabe destacarar, como guía válida para enmarcar el presente estudio, las aportaciones del materialismo anglosajón; véanse, por ejemplo, Joseph STRAYER, The Costs and Profits of War: the Anglo-french Conflict of 1294 1303, en Harry MISKIMIN; David HERLIHY; Abraham L. UDOVITCH (eds.) The Medieval City, New Haven-Londres, Yale University Press, 1977 , pp. 269-291; Kenneth B. MCFARLANE, War, Economy and Social Change. England and the Hundred Years War, "Past and Present" 22 '(Julio1962) pp. 3-13; Michael POSTAN, The Costs of the Hundred Years' War. "Past and Present" 27 (Abril-1964), pp. 34-53; Michael PRESTWICH, Armies and Warfare in the Middle Ages : the English Experience, New Haven-Londres, Yale University Press, 1996. Son básicas también, las aportaciones de Philippe CONTAMINE, Guerre, Etat et Société à la fin du Moyen Age. Etudes sur les armées des rois de France, 1337-1494, París-La Haya, Mouton, 1972; IDEM, La guerra en la Edad Media, Barcelona, Labor, 1984; de Claude GAIER, Art and organization militaires dans le principauté de Liège et dans le comté de Looz au Moven Age, Bruselas, Palais des Académies, 1968 y de Aldo A. SETTIA, Rapine, assedi, battaglie. La guerra nel Medioevo, Roma-Bari, Editori Laterza, 2002. Como síntesis y resúmenes relativamente recientes del camino marcado por las distintas corrientes, véanse John W. CHAMBERS, Conference Review Essav: The New Military History: Mith and Reality, "The Journal of Military History", 55-3 (Julio-1991), pp. 395-406, y John FRANCE Recent Writing on Medieval Warfare: From the Fall of Rome to c. 1300," "The Journal of Military History", 65-2 (Abril-2001), pp. 441-473; para el ámbito peninsular véase Manuel FLORES DÍAZ, Historia militar y naval española medieval. Un acercamiento al estado de la cuestión, "eHumanista", 10 (2008) pp. 244-273. Lamentablemente, las innovaciones historiográficas descritas más arriba apenas han llegado al ámbito de la Corona de Aragón ni a su historiografía militar, ya de por sí escasa y, en buena medida, pendiente de sumarse a dicho proceso de cambio. Pese a la escasa bibliografía existente para tratar esta temática en la Corona de Aragón, se debe destacar la aportación de obras, tan interesantes como aisladas, como las de Jorge SÁIZ SERRANO, Guerra y nobleza en la Corona de Aragón. La caballeria en los ejércitos del Rey (Siglos XIV-XV), tesis doctoral inédita (agradezco al Dr. Sạiz que me autorizase a acceder al manuscrito antes de su publicación en red); IDEM, La organización militar en la expansión mediterránea de la Corona de Aragón, en Rafael NARBONA VIZCAÍNO (ed.) La Mediterrania de la Corona d'Aragó, segles XIIIXVI \& VII centenari de la sentència arbitral de Torrellas, 1304-2004. XVIII Congres d'Historia de la Corona d'Aragó, Valencia, Universitat de València, Fundació Jaume II el Just, 2004, vol. 1, pp. 737-764: J. Angel SESMA MUNOZ, Guerra, ejército y sociedad en los reinos de Aragón y Navarra en la Edad Media, "Revista de Historia Militar", nº extraordinario (2002), pp. 13-48. Destaca también la extensa bibliografía de Maria Teresa Ferrer i Mallol en la que sobresalen algunos estudios básicos para este trabajo, como Maria Teresa FERRER I MALLOL, Organització $i$ defensa d'un territori fronterer. La governació d'Oriola en el segle XIV, Barcelona, CSIC, 1990; EADEM, La organización militar en Cataluña en la Edad Media, en Miguel Angel LADERO QQUESADA (coord.) Conquistar y defender: Los recursos militares en la Edad Media hispánica, "Revista de Historia Militar", número extraordinario (2001), pp. 119-222. Permanece, desdichadamente, inédita la pionera aportación de Manuel SÁNCHEZ MARTínEZ, La Corona de Aragón y el reino 
El presente estudio se enmarca en la conjunción entre la realidad de la Corona de Aragón en el Mediterráneo y el desarrollo de los aparatos militares de monarquías y ciudades-estado. En pleno crecimiento de la escala cuantitativa de los conflictos armados - una forma más del objeto de estudio que ocupa estas páginas- el control de territorios y vías de importancia geoestratégica, la movilización de grandes contingentes de gente de armas y el desarrollo de sistemas de logística para mantenerlos operativos se concatenaron, sin que sea posible distinguir completamente las causas de los efectos, moldeando en el proceso la historia militar, política, económica y social del occidente bajomedieval. La monarquía catalanoaragonesa, lejos de permanecer ajena a estas dinámicas, se sumó a ellas, partiendo de su secular tradición militar y desarrollando, con cada reto y cada respuesta, un conjunto único de métodos destinados a servir a sus intereses en numerosas guerras.

Este trabajo pretende mostrar el funcionamiento y la interacción de factores políticos, geoestratégicos, operacionales y logísticos, partiendo del estudio de caso de una armada comandada por Pedro el Ceremonioso, en 1354, en Cerdeña, uno de los teatros de operaciones de mayor dificultad para las armas catalanas. De este modo, además de tratar de profundizar en la campaña descrita, se intentará definir, a partir de los detalles de la misma, algunas condiciones generales de la presencia catalana en la isla, así como trazar un perfil de los límites que condicionaron la potencia política y militar de la Corona de Aragón en Cerdeña y en el Mediterráneo.

\section{CONDICIONANTES PARA UNA CAMPAÑA}

\section{Los precedentes inmediatos: la guerra contra Génova, Alguer y el juez de Arborea}

Las complicadas relaciones de la casa de Aragón con sus vasallos y competidores en torno a la isla de Cerdeña y al Mediterráneo occidental exceden las posibilidades de este trabajo y ya han sido, por otra parte, bien estudiadas ${ }^{4}$. La pugna de entre catalanes y genoveses - destacando los linajes de los Malaspina y los Doria- fue intermitente, renovándose con especial acritud entre 1333 y 1336, con el mar como escenario principal de una continua guerra

nazarí de Granada en el siglo XIV: las bases materiales y humanas de la cruzada de Alfonso IV (1329-1335), tesis doctoral inédita (agradezco al Dr. Sánchez que me proporcionase el manuscrito).

${ }^{4}$ Vicente SALAVERT I ROCA, El problema estratégico del Mediterráneo occidental y la política aragonesa (siglos XIV y XV), en IV Congreso de Historia de la Corona de Aragón, Mallorca, Diputación provincial de Baleares, 1955, pp. 201-221; Marina MITJÁ, Barcelona y él problema sardo en el siglo XIV, en VI Congreso de Historia de la Corona de Aragón, Madrid, Dirección general de relaciones culturales del Ministerio de Asuntos Exteriores, 1959 ; pp. 447-459; véase ante todo Giuseppe MELONI, Genova e Aragona all'epoca di Pietro il Ceremonioso, Padua, CEDAM, 1971, vol. 1, pp. 181-213. Para un marco global de la presencia catalana y del tardmedievo sardo, véase Francesco Cesare CASULA, La Sardenya catalano-aragonesa: perfil históric, Barcelona, Rafael Dalmau, 1985. Resulta también imprescindible para este estudio Luisa D'ARIENZO, Carte reali diplomatiche di Pietro il Cerimonioso, re d'Aragona, riguardanti l'Italia, CODOIN, vol. 45, Padua, CEDAM, 1970. 
de desgaste económico. Conviene destacar que, en 1347, en la batalla de Aidu du Turdu, las fuerzas genovesas en Cerdeña infligieron una durísima derrota a las armas catalanas, llegando a amenazar Sassari, y poco después los Doria entregaron la ciudad de Alguer, infeudada a éstos por el rey de Aragón, a la jurisdicción del común ligur. El principal valedor de los intereses de la Casa de Aragón en Cerdeña era, desde el primer desembarco catalán en 1323, el juez de Arborea. Vasallos del rey pero del todo soberanos en sus posesiones, Hugo y Pedro de Arborea apoyaron la causa aragonesa, aprovechándola para actuar contra la presencia pisana en la isla y salvando a sus aliados catalanoaragoneses en ocasiones tan desventajosas como la de 1347, siendo ya Mariano IV el juez. Como se verá, la revuelta de 1353 iba a suponer un cambio absoluto de rumbo del linaje judical y de la historia del Regnum Sardinie.

Mancomunando esfuerzos con Venecia, rival de los genoveses en sus mercados orientales y en aguas de todo el Mediterráneo, Pedro IV firmó un tratado de alianza ${ }^{5}$. Éste se tradujo en el armamento de una poderosa flota que, en 1351, partió hacia oriente, se reunió con la fuerza naval veneciana y acabó obteniendo, en una dura batalla en aguas del Bósforo en 1352, una victoria pírrica contra los genoveses ${ }^{6}$. Lejos de detener las hostilidades, Pedro el Ceremonioso y la Serenísima armaron, en 1353, una nueva flota conjunta que se dirigió a aguas de Cerdeña e infligió, el 27 de julio, en Porto Conte, frente a la costa de Alguer, una durísima derrota a la flota genovesa ${ }^{7}$. Este hecho derivó en la inmediata rendición de Alguer al capitán general Bernat de Cabrera, y en la entrega de la señoría del común de Génova a Giovanni Visconti, señor de Milán, bajo cuyos auspicios y ayuda trató aquél de compensar su apurada situación politicomilitar.

Ya en ese momento, sin embargo, la situación de los aliados de Pedro IV había cambiado: En otoño de 1353, Mariano IV, juez de Arborea, rompía su vasallaje rebelándose contra su rey y atacaba a sus antiguos aliados catalanoaragoneses. Debe señalarse que en la revuelta judical se encuentra sin duda uno de los mayores puntos de inflexión de la historia del regnum Sardinie y de la presencia catalana en él. Todas las ecuaciones geoestratégicas, militares, políticas y económicas que habían regido las relaciones de los poderes de la isla se habían invertido.

\section{Condicionantes geográficos}

El contexto geográfico es, fuera de toda duda, un esqueleto primordial para las sociedades humanas que, aunque sean capaces de transformarlo, se desarrollan a partir de él. No menos aplicable es esta máxima a cualquier iniciativa política, económica y militar, que encuentra en el espacio, en el

\footnotetext{
${ }^{5}$ Véase José Vicente CABEZUelo PLIEGo Diplomacia y guerra en el Mediterráneo medieval. La liga véneto-aragonesa contra Génova de 1351, "AEM", 36-1 (enero-junio 2006), pp. 253-294. ${ }^{6}$ Michel BALARD, À propos de la bataille du Bosphore. L'expédition génoise de Paganino Doria à Constantinople (1351-1352), "Travaux et mémoires" 4 (1970), pp. 431-469.

${ }^{7}$ Pedro IV, Crónica, V-20.
} 
terreno, en las comunicaciones y en los recursos naturales un camino del que no puede desviarse sin graves consecuencias, acaso definitivas, para consecución de sus objetivos. La geografía de Cerdeña es tanto causa como consecuencia de los avatares politicomilitares de la isla, pues en su situación insular y en sus recursos radica tanto la importancia como la dificultad de su posesión y control.

\section{a) El mar: motivación, vía y obstáculo para el control de Cerdeña}

Desde el primer momento de su expansión marítima, la casa de Aragón centró su atención en el Mediterráneo — en palabras del propio Jaime $\mathrm{I}^{8}$ — como espacio de crecimiento territorial y económico. Como defínió magistralmente Ramon Muntaner en el Sermó que, inserto en su crónica, dirigió al infante Alfonso para la conquista de la isla ${ }^{9}$, Cerdeña fue un punto de particular importancia en la expansión catalanoaragonesa ${ }^{10}$. La isla era una de las principales escalas de navegación, desde y hacia la costa oriental de la Península Ibérica, que conectaba con las principales rutas marítimas de la época ${ }^{11}$.

La navegación en la cuenca occidental del Mediterráneo, dependiente de vientos y corrientes, es más fácil de norte a sur que en dirección contraria ${ }^{12}$. La autonomía de los barcos de la época obligaba a no alejarse demasiado de la costa y a realizar frecuentes escalas, ante todo en caso de moverse en una ruta que, contra la tendencia antes mencionada, remontara cualquiera de las costas de la zona hacia el norte. Era precisamente la posesión de estas plazas y estaciones insulares lo que provocaba la mayoría de choques - entendidos

\footnotetext{
${ }^{8}$ “...e en semblant que aquest feyt de que vos nos havets parlat de conquerir lo regne de Mallorques qui es dins mar, que us serà major honrament que si en conqueríets tres en terra..."; JAIME I, Llibre dels feyts, LVI.

${ }^{9}$ Aunque todo el sermón dirigido al infante Alfonso está repleto de alusiones a la mar y a la talasocracia, destaça el pasaje siguiente: "Per ço hai començat en lo fait de la mar, / car la mar cové tenga cell qui vol conquistar / lo regne de Sardenya; ẻ si ho fai, tremblar / farà trastot lo mon..." (R. MUNTANER, Crónica, CCLXXII).

${ }^{10}$ Véase el magnífico trabajo de V. SALAVERT, El problema estratégico del Mediterráneo, pp. 201-221. La conquista de la isla revistió gran importancia, tanto, por un lado, desde la óptica política de la monarquía como, por otro, para la extensión de los mercados hacia el norte de Africa y oriente, procesos distintos pero con un desarrollo paralelo y a menudo asociado; véase Antoni RIERA MELIS, Barcelona en els segles XIV $i X V$, un mercat internacional a escala mediterrània, "Barcelona, quaderns d'històra", 8 (2003), pp. 65-83, p. 82. Resulta imprescindible para este particular la aportación de Mario DEL TREPPO, Els mercaders catalans $i$ t'expansió de la Corona catalano-aragonesa al segle XV, Barcelona, Curial, 1976, pp.15-67.

${ }^{11} \mathrm{Sin}$ ánimo de entrar en el debate en torno a la ruta de las islas y la ruta de las especies, podemos considerar, siguiendo a Damien Coulon, "que la expansión catalana seguía una línea que "Plutôt que d'être associée à la "route des épices", la "route des îles" constitué donc avant tout un axe privilégié de navigation à travers la Méditerranée"; véase Damien CoULON, Barcelone et le grand commerce d'Orient au Moyen Age: un siècle de relations avec l'Egypte et la SyriePalestine (ca. 1330-ca. 1430), Madrid- Barcelona, Casa de Velázquez- Institut Europeu de la Mediterrània, 2004, pp. 198-200. Véase también Marco TANGHERONI, Aspetti del commercio dei cereali nei Paesi della Corona d'Aragona. 1-La Sardegna, Pisa, Pacini, 1981, pp. 51-65, así como el trabajo de M. Del Treppo, cit. en la nota anterior.

${ }^{12}$ John PRYOR, Geography, technology, and war. Studies in the maritime history of the Mediterranean, Nueva York-Melbourne-Cambridge-New Rochelle-Sydney, Cambrige University Press, 1988, p. 89.
} 
como conflictos de cierta magnitud entre entes públicos - entre poderes que se disputaban su dominio ${ }^{13}$.

El Mediterráneo noroccidental, obviamente, no era ni podía ser objeto de control absoluto por parte de la Corona de Aragón. Génova, vecina y rival de los reyes de Aragón en el ámbito político, gobernada por una élite que competía con los catalanes en buena parte de sus mercados, también buscaba el control geográfico de la navegación. La importancia de los refugios naturales y concentraciones de hábitat, industria e intercambio se acentuaba en el caso de la isla de Cerdeña. Su costa occidental es la más próxima al eje principal de comunicaciones y de producción agrícola de la isla ${ }^{14}$ pero corre paralela a él, enlazándose una y otro en pocos puntos. Ésta, además, es escarpada y presenta pocas áreas extensas de playa arenosa y aún menos bahías que actúen de puertos naturales ${ }^{15}$. La posesión de estos puntos clave resultaba, pues, básica para la navegación en una zona tan complicada como la que nos ocupa, y permitía a la vez extraer y controlar — con las limitaciones de la época, pues no cabe pensar en monopolios cerrados - los stocks agropecuarios y mineros que abundaban en la isla y de los que eran deficitarias tanto la Corona de Aragón como Génova $^{16}$. Si la costa sarda occidental se hallaba entre los objetivos prioritarios en litigio, no menos importante era el control del estrecho de Bonifacio, punto clave de la navegación del Mediterráneo occidental y de abundantísimo tráfico marítimo ${ }^{17}$.

${ }^{13}$ La escasa capacidad de carga de los barcos, principalmente los de remos, no permitía transportar gran volumen de agua y provisiones para el personal embarcado, por lo que las escalas eran frecuentes y su control revestia gran importancia; J. PRYOR, Geography, technology, and war, pp. 76-79. El control de los puntos apropiados de una costa concreta no sólo daba la opción a los barcos propios de recalar de forma segura, sino que también cerraba el refugio a un posible enemigo y permitía que sirviesen de base para acciones de corso. El caso de la isla de Cerdeña es paradigmático en este sentido, pues, si fue base privilegiada para el comercio, de igual modo lo fue para el corso, práctica muy extendida en aguas sardas que se convirtió en un componente estructural de la economía, la política y la conflictividad de la zona; véase Pinuccia Franca SIMBULA, Corsari e pirati nei mari di Sardegna, Cagliari, Istituto sui Rapporti Italo-IbericiConsiglio Nazionale delle Ricerche, 1993.

${ }^{14}$ Véase infra, apartado siguiente.

Porto Torres, Alguer, Bosa, Oristano, Palma di Sulcis y la bahía de Cagliari eran los únicos espacios apropiados para fondear e intercambiar con garantías en la costa occidental sarda. Cabe destacar, Mlegado este punto, la importancia de Alguer como centro neurálgico de los conflictos que azotaron Cerdeña en el ecuador del siglo XIV. Situada en una bahía protegida de los vientos del norte y el noroeste, comunicaba cómodamente con el interior de la isla y, además, disponía de una potente fortificación; véase Angelo CASTELLACCIO, Le fortificazioni e le strutture difensive di Alghero (XIV-XV secolo), en Antonello MATTONE; Piero SANNA, Alghero, la Catalogna, il Mediterraneo. Storia di una città e di una minoranza catalana in Italia (XIV-XX secolo), Sassari, Gallizzi, 1994, pp. 125-148. La ciudad fue un punto estratégico vital y por ello cambió de manos repetidas veces en los años anteriores a su definitiva conquista por Pedro el Ceremonioso, con lọs Doria y el común de Génova resistiéndose a los intentos catalanes de tomarla. No sólo. éstos, sin embargo, eran agentes directos del conflicto. Mariano de Arborea, señor de Bosa y Oristano, trató de ampliar su dominio a Alguer, como se subrayará más adelante; véase infra, nota 45

${ }^{16}$ Se volverá sobre éstos más adelante, pero por el momento véase M. TANGHERONI, Aspetti del commercio, pp. 67-75.

${ }^{17}$ Cabe recordar que la infeudación del Papa Bonifacio VIII a Jaime II representaba una licencia invadendi para Cerdeña y también para Córcega, teóricamente unidas en el Regnum Sardiniae et Corsicae. El control del estrecho fue, de hecho, uno de los objetivos prioritarios catalanoaragoneses, ya que los continuos estallidos violentos con los Doria del norte de la isla invitaban a las autoridades catalanas a reforzar su posición en la zona, asegurando así las comunicaciones de Sassari con los reinos metropolitanos a través de los puertos -variando éstos en función de la coyuntura política- de Porto Torres o Alguer. Los oficiales de Pedro el 
Sin embargo, conviene subrayar que si el mar y su dominio estuvieron entre las causas principales de la conquista de Cerdeña, fueron también, paradójicamente, un obstáculo para su control efectivo por parte de las autoridades catalanoaragonesas, tanto por las dificultades propias de la navegación como a causa de la potencia naval de la república de Génova.

\section{b) Cerdeña: territorio y economía de un escenario de guerra}

No menos importante en la configuración de la presencia catalanoaragonesa de la isla fueron, junto al mar y sus particulares problemas y beneficios, el traspaís agrícola y el territorio interior de Cerdeña. La distribución del relieve, de los recursos mineros y agropecuarios, de las comunicaciones y de las plazas fortificadas - centros de control político y militar tanto como económicomarcaba el devenir de los conflictos que envolvieron las posesiones catalanoaragonesas en sus primeros años de presencia en la isla, y resultó decisiva en la configuración del momento de radical mutación que representó la revuelta arborense. No cabe entrar aquí a analizar los motivos económicos que llevaron a la Casa de Aragón a la conquista y defensa - desigualmente afortunada - de Cerdeña, pero parece claro el hecho de que sus stocks agropecuarios y sus recursos mineros estuvieron entre las causas de mayor peso ${ }^{18}$.

Se ha hablado de varios puntos cruciales de las costas sardas, que destacan por su facilidad para enlazar con el eje de llanuras cerealícolas que cruza la mitad oriental de la isla de norte a sur, separado del mar por el difícil relieve de la $\operatorname{costa}^{19}$. Su importancia radica en su condición de llanura aluvial,

Ceremonioso intentaron, en 1353, tomarle al común de Génova la plaza de Bonifacio (Córcega) con ayuda de los della Rocca, linaje corso proaragonés (Maria Giuseppina MELONI, Arrigo della Rocca: un nobile corso al servizio del re d'Aragona "Medioevo, Saggi e Rassegne", 18 (1994), pp. 9-26) y, al mismo tiempo, el castillo y la villa de Castelgenovese en el norte de Cerdeña. Bonifacio permaneció en manos genovesas, mientras que Castelgenovese, hoy llamado Castelsardo, pasó por breve tiempo a manos catalanas, tras un hábil y șangriento golpe de mano nocturno que el propio gobernador de la isla refirió a Pedro el Ceremonioso (ACA, $C, C R, P e d r o$ III, caja 42, c. 5183. Castelgenovese, 1353, julio, 29. Regestada en L. D'ARIENZO, Carte reali, doc. 406). La importancia de estas posiciones genovesas que așeguraban la presencia ligur en el estrecho, puede verse en las palabras de Martino de Moro, vicario del castillo de Bonifacio, que se lamentaba de la pérdida de Castelgenovese en una carta enviada a Aaron Doria (ACA, $C$, CR, Pedro III, caja 42, c. 5176. Bonifacio, 1353, agosto, 1. Regestada en L. D'ARIENZO, Carte reali, doc. 402), en la que escribía que el estrecho de Bonifacio "era murao de doe mure, l'um si he la Rege [de Bonifacio] e l'atro se era Castelzenoese"

${ }^{18}$ Los derivados de la actividad ganadera estuvieron entre las materias más comúnmente exportadas desde la isla hacia los reinos de la Corona de Aragón, véase A. RIERA, Barcelona, pp. 73-74. Cabe destacar también la relación con mercados y mercaderes extranjeros que, al no estar bajo las exenciones concedidas por los reyes de Aragon, pagaban derechos aduaneros por sus trấficos, principalmente por la sal extraída en el área de Cagliari y por el comercio de trigo, vẹase M. TANGHERONI, Aspetti del commercio, pp. 150-158. A todos estos recursos naturales conviene sumar, sin lugar a dudas, la plata de Iglesias - città dell'argento, en palabras de Marco Tangheroni- cuyo territorio era rico en yacimientos metalíferos que alimentaron una activísima ceca, véase M. TANGHERONI, La città dell'argento: Iglesias dalle origini alla fine del Medioevo, Nápoles, Ligouri, 1985.

${ }^{19}$ Este eje, aún hoy columna vertebral de las comunicaciones en Cerdeña, seguía el trazado de la principal vía romana de la isla y enlazaba Sassari con Cagliari, pasando por Bosa y Oristano -posesión y capital judicạl respectivamente- y ramificándose desde Sassari hasta Porto Torres y Alguer y desde Cagliari hasta Igleșias. Resulta útil, para la descripción de las vías terrestres de comunicación, el trabajo de Massimo RASSU, Pellegrini e Templari in Sardegna, Cagliari, Artigianarte, 1997 (no me ha sido posible consultar esta obra), así como Emilio BELLI, Le vie di 
que facilita tanto el paso de un camino de rueda amplio como la presencia de cultivos cerealícolas ${ }^{20}$.

La conquista de los territorios pisanos permitió a las autoridades catalanoaragonesas el control de los recursos naturales del sur de la isla ${ }^{21}$. Sin embargo, algunas de las principales zonas cerealícolas del centro de la isla no estaban bajo control directo del realengo catalán. Por una parte, las productivísimas curatorías de Ghippi y Trexenta se hallaban infeudadas al común de Pisa - que tenía derecho a extraer trigo de ellas - mientras que las enormes reservas granarias del Campidano, en el centro de la isla, pertenecían al Juez de Arborea $^{22}$. A la luz de la documentación, el grano parece hallarse, junto a otros muchos factores, en la base de la mayoría de disputas del común toscano y, ante todo, del juez de Arborea con los oficiales de Pedro IV y con el mismo monarca $^{23}$.

Si el común de Pisa pugnaba por proteger sus derechos sobre los recursos de sus áreas de influencia, Mariano de Arborea pudo ejercer de árbitro de la situación política y militar de la isla. Los stocks de grano que controlaba le permitían armar poderosos ejércitos y apoyar a sus aliados catalanes en difícultades ${ }^{24}$. Una vez rotas las relaciones con las autoridades regias, en octubre de 1353, el juez empleó, como se verá más adelante, sus capacidades

comunicazione della Sardegna medievale, en Ugo CRISPONI, Enrico LOI, Alberto MONTEVERDE (eds.), Milites. Castelli e battaglie nella Sardegna tardo-medievale, Cagliari, Regione Autonoma della Sardegna-Assessorato alla Cultura della Provincia di Cagliari-Università di CagliariFondazione Banco di Sardegna-Embajada Española, 1996, pp. $77-86$.

${ }^{20} \mathrm{El}$ relieve montañoso de la isla, principalmente del centro y del norte de la misma, es poco favorable para el cultivo y el transporte, a excepción del área de la Gallura, en buena parte controlada por los Doria. Se subrayan algunos de los principales aspectos geográficos del problema en A. CASTELLACCIO, Utilizzazione militare di alcune acque interne nella Sardegna catalano-aragonese, en Manlio BRIGAGLIA (ed.), La Sardegna nel mondo mediterraneo. Atti del terzo convegno internazionale di studi geografico-storici, Sassari - Porto Cervo- Bono, 10-14 aprile 1985. 6-Per una storia dell'acqua in Sardegna, Sassari, Istituto Superiore Regionale Etnografico di Nuoro-Gallizzi edizion1, 1990, pp. 83-116. Véase también Angela TERROSU ASOLE, Roberto PRACCHI; Matteo RICCARDI, Atlante della Sardegna, Cagliari, Edizioni Laterza, 1971; no me ha sido posible consultar esta obra.

${ }^{21}$ La política anonaria de la monarquía le aseguraba rentas constantes y el control sobre un recurso básico como el cereal, escaso en su señoría, codiciado por los principales municipios - cabe destacar aquí el papel de Barcelona- y, por todo ello, excelente moneda de cambio para negociar con ellos, véase Pere ORTI GOST, El forment a la Barcelona baixmedieval: preus, mesures $i$ fiscalitat (1283-1345), "AEM", 22 (1992), pp. 377-423; Jordi MORELLO BAGET; Christian GUILLERÉ, Aprovisionement et finances municipales en Méditerrané occidentale: l'exemple de la Couronne d'Aragon, en Denis MENJOT; M. SÁNCHEZ (coords.), La fiscalité des villes au Moyen Age (Occident Méditerranéen).3-La Redistribution de l'impôt, Lyon-Barcelona, CNRS-CSIC, 2002,pp.267-294: Mario LÁZARO ORSI, L'autoritat municipal de Barcelona davant el Mal Any Primer. Estudi de l'actuació del Consell de Cent a través de la seva correspondència, "Ex Novo", 1 (Febrero 2005), pp. 67-91.

${ }^{22}$ Tanto Pisa como Mariano IV tuvieron la posesión de tan preciado recurso como eje primordial de sus capacidades y demandas políticas; véase M. TANGHERONI, Aspetti del commercio, pp. 128-142. El potencial anonario de los territorios judicales se subraya en F. CASULA, Nuovi documenti per la storia economica della Sardegna aragonese "Archivio Storico Sardo" 30 (1976), pp. 58-68. Debo y agradezco esta referencia a Giacomo Floris.

${ }^{23}$ Pedro el Ceremonioso y sus oficiales emitieron repetidas quejas y prohibiciones al juez, a fin de que impidiese el tráfico de granos de sus tierras a los Doria, rebeldes al rey y aliados con sus enemigos públicos genoveses, que retenían Alguer en sụ poder. Igualmente, las disputas de Mariano IV con su hermano Juan -tanto en torno a la posesión de Bosa como relativas a feudos ofrecidos por el rey en la Gallura, fuera de territorio judical- pueden interpretarse en esta misma dirección.

${ }^{24}$ Véase supra, nota 4. 
económicas para financiar un considerable despliegue político y militar, uniendo esfuerzos con Génova y Milán contra el enemigo catalanoaragonés. Éste se halló repentinamente privado del principal aliado para su logística militar en Cerdeña: los oficiales regios no sólo vieron impotentes cómo el grano de las tierras del juez se drenaba desde sus manos hasta las de los enemigos genoveses, sino que se hallaron imposibilitados para comunicar, como parcialmente hacían hasta el momento, Cagliari y Sassari. Los sardos judicales cortaban en dos el principal camino de la isla, y lo usaban para devastar o saquear los recursos que los súbditos de Pedro IV conservaban en el Cagliaritano y el Iglesiente.

Este estado de cosas dificultaba seriamente cualquier tipo de futura acción militar catalanoaragonesa, no sólo a causa de las insuficientes reservas anonarias que habían quedado en manos de los oficiales regios sino también, y conviene subrayar este hecho, por el perfil demográfico y económico de la isla de Cerdeña. Cualquier ejército de maniobra operando en territorio enemigo, aun contando con un tren de suministros o con una línea de abastecimiento, buscaba, en la medida de lo posible, ahorrar en el consumo de las propias reservas de provisiones. Ello podía conseguirse pactando o comerciando con las poblaciones locales $^{25}$ o bien, en caso necesario, forrajeando ${ }^{26}$; este último sistema, además, permitía compensar el gasto que suponía sostener un ejército en campaña y contribuía a mantener altas la moral y la motivación de la tropa, dando opciones de botín a los soldados y evitando que estuviesen ociosos durante demasiado tiempo. Éste era un difícil procedimiento en Cerdeña, caracterizada por unas estructuras demográficas y económicas que no lo favorecían $^{27}$. Pese a que la isla, como ya se ha comentado, era territorio de

${ }^{25}$ Un ejército de maniobra con intención de moverse debía, en palabras de Nadia Covini, avere il paese amico, consiguiendo, mediante la fuerza, el pacto, la coacción o cualquier otro medio, la colaboración de la población y de las fuerzas vivas locales; véase Nadia CoVINI, "Studiando el mappamondo": Trasferimenti di genti d'arme tra logiche statali e relazioni con le realtà locali, en Sergio GENSINI (ed.), Viaggiare nel medioevo, San Miniato, Pacini editore, 2000, pp. 227-266, y sobre este particular principalmente pp. 232-236.

${ }^{26}$ Esta palabra, más allá de su signifiçado relacionado con la búsqueda de forraje, tiene una acepción propiamente militar, en la que significa moverse y saquear en busca de alimento para la tropa y las bestias.

${ }^{27}$ Sin pretensión de seguir aquí los debates planteados alrededor del poblamiento y el desarrollo económico de la isla, es imprescindible tenerlos en cuenta como condicionante crítico para entender el desarrollo de la campaña que nos ocupa. Conviene destacar, por ejemplo, el debate alrededor de los conceptos de población y desarrollo planteado por John Day en trabajos como John DAY, Malthus dementi? Sous-peuplement chronique et calamités démographiques en Sardaigne au Bas Moyen Age "Annales. E.S.C.", 30 (1975), pp. 684-702; e IDEM, L'economia de la Sardenya catalana, en Jordi CARBONELL; Francesco MANCONI, Els catalans a Sardenya, Barcelona, Enciclopèdia Catalana, 1984, pp. 15-24. Esta línea de hipótesis generó interesantes aportaciones como la de M. TANG̣HERONI, I diversi sistemi economici: Rapporti e interazioni. Considerazioni generali e analisi del caso sardo, en IDEM, Medioevo tirrenico. Sardegna, Toscana e Pisa, Pisa, Pacini, 1992 , pp. 35-63. Véase también Carlo LIVI, La popolazione della Sardegna nel periodo aragonese, "Archivio Storico Sardo", 34-2 (1984), pp. 23-130. Sobre el poblamiento y su estructura dispersa o concentrada, véase Giovanni MúRGia, La conquista aragonese e il crollo dell'insediamento abitativo rurale sparso nella Sardegna dei secoli XIV-XV en R. NARBONA (ed.), La Mediterrània de la Corona d'Aragó. XVIIII Congrés d'Història de la Corona d'Aragó, pp. 285-305. De uno u otro modo, se puede considerar que la economía y la demografía de Cerdeña, tras los cambios derivados de la presencia pisana y catalana y pensando en la confliçtividad omnipresente en la isla -ante todo en la zona noroccidental- en el segundo tercio del siglo XIV, no estaban en la mejor situación para soportar la presencia de ejercitos numerosos, que con su mera presencia desequilibraban de modo nefasto la balanza entre población y recursos. Resulta prueba fehaciente de este hecho, como se comentará más adelante, 
excedentes agropecuarios, un ejército de maniobra tendría problemas para acceder a ellos sin dispersar sus fuerzas - grave riesgo en territorio enemigoen acciones de rapiña. Incluso en ese caso, el poblamiento disperso debió de ser un obstáculo para el saqueo, mientras que, probablemente, la fuerte incidencia de la ganadería en la economía de la isla facilitaría la migración y el traslado de los bienes semoventes, lejos del alcance de los forrajeadores ${ }^{28}$.

Por fin, no menos importancia se debe conceder, como marco geográfico a la problemática estudiada, a un fenómeno connatural a la Cerdeña del siglo XIV: la malaria. Potenciada por el clima caluroso y por la presencia de zonas pantanosas, era un mal endémico en la isla, que golpeó a los ejércitos que trataron de operar en ella y disuadió a numerosos repobladores catalanoaragone$\operatorname{ses}^{29}$.

Una vez más, la distribución de recursos económicos, enlazada con la configuración del territorio, había constituído uno de los principales motivos de interés de los monarcas de la Casa de Aragón y sus súbditos en la isla de Cerdeña. Tal vez por ello mismo, se volvió en su contra cuando la revuelta judical cambió la ecuación de fuerzas en la geopolítica sarda y mediterránea, en verano de 1353.

\section{Condicionantes políticos y militares: Génova, el señor de Milán y el Juez de Arborea}

En la difícil coyuntura que vivieron los dominios de Pedro IV en Cerdeña intervinieron, además del medio natural y económico, acciones llevadas a cabo por sus enemigos, en cuyas especificidades merece la pena fijar la atención. Las situación de las fuerzas militares y las instituciones políticas catalanoaragonesas dependió no sólo de sus limitadas posibilidades, sino también de las particularidades sociales, políticas y económicas que condicionaban las opciones militares de Génova y del juez de Arborea.

la constante necesidad de llevar grano para el ejército a la isla durante la expedición regia, pero también, y esțo debe subrayarse, despues de terminar la campaña; véase M. TANGHERONI, Aspetti del commercio, 101-103.

${ }^{28}$ De hechọ, la circulạción de botín en los ejércitọs catalanes se centraba en buena medida en ganado cárnico, pero siempre, pese a la abundancia de éste en tierras sardas, en cantidad insuficiente, véase infra, nota 94.

${ }^{29}$ Cabe destacar, por ejemplo, los entornos de la bahía de Cagliari y las áreas paludosas de la curatoría de Decimo, al sur de la isla, como zonas de pantanos propensas a favorecer la propagación de la enfermedad. En el norte, sin embargo, no faltaron condiciones que potenciasen los efectos dañinos de la malaria en las aglomeraciones propias de los ejércitos, siempre vulnerables a las epidemias y más aún cuando permanecian demasiado tiempo estáticos o desabastecidos. Cabe destacar que, durante los últimos momentos de la campana de 1354, el propio rey Pedro sufría fiebres, probablemente de malaria, lo que debió de ayudar a que Bernat de Cabrera, pese a la obstinación del convaleciente rey, abogase por el pacto con sus enemigos, como se relata en J. ZURITA, Anales, VIII-57; más lejana es la mención a la malaria y a los enfermos del ejército, obviando la convalecencia del monarca, en PEDRO IV, Crónica, VI-38. Véase también la mención a la insalubridad y a los brotes de malaria en Cerdeña analizados en Lluís CIFUENTES COMAMALA, Medecina $i$ guerra a l'Europa baix-medieval: la sanitat i la participació dels seus professionals en les expedicions militars de la Corona d'Aragó (13091355), tesis doctoral inédita, vol. 2, pp. 416-420. Agradezco al Dr. Cifuentes que me proporcionase el manuscrito. 


\section{a) Génova: una potencia naval concentrada en Oriente}

Tras los mencionados reveses sufridos por Génova en el verano de 1353 - la derrota de Porto Conte y la toma de Castelgenovese y Alguer por los catalanoaragoneses - todo apuntaba a una crisis de efectivos ${ }^{30}$ y a una reducción de la presencia política del común ligur en Cerdeña. No obstante, Génova, presionada por su situación interna y por los constantes ataques venecianos, entregó la señoría de la ciudad a Giovanni Visconti, señor de Milán. Gracias a este importante refuerzo en forma de inyección económica a la guerra y, a la vez, de apoyo diplomático, el común ligur se halló en condiciones de poner en el mar nuevas y potentes flotas de galeras ${ }^{31}$ mientras que, con la revuelta de Mariano de Arborea, las posiciones catalanas en la isla no se hallaban precisamente en situación ventajosa. Como ya se ha dicho, cualquier futura expedición de los hombres del Ceremonioso tendría graves dificultades para acceder a los recursos básicos controlados por sus enemigos y necesitaría, por ello, un tren de abastecimiento o incluso una constante línea de suministros procedentes de los reinos metropolitanos de la Corona ${ }^{32}$.

Conscientes de ello, los genoveses dieron prioridad al choque frontal con Venecia en oriente y dejaron en segundo plano las aguas sardas. La situación de las flotas aliadas favorecía esta decisión. Ante la necesidad de apoyar la expedición regia en la isla y temerosos de sufrir nuevas bajas en aguas

${ }^{30}$ Las pérdidas genovesas en Porto Conte ascendieron a cifras del volumen de 8 galeras capturadas, 3000 muertos y 800 cautivos (PEDRO IV, Crónica, V-20). Las galeras fueron repartidas como presas y los cautivos corrieron la misma suerte, distribuidos como botín entre los municipios de realengo catalán -financiadores, en última instancia, de la campaña-, que los cedieron a particulares y los utilizaron en todo tipo de trabajos pesados relacionados con la posterior armada aquí estudiada; véase, por ejemplo, Álvaro SANTAMARÍA ARÁNDEZ, Cautivos genoveses en Mallorca durante las campañas sardas de 1353-1355, "AEM", 5 (1968), pp. 501516; Albert ESTRADA-RIUS, La drassana reial de Barcelona a l'Edat Mitjana. Organització institucional $i$ construcció naval a la Corona d'Aragó, Barcelona, Museu Marítim de Barcelona 2004, pp. 124-127. Abundan, a lo largo del invierno y la primavera de 1354, las referencias a éstos en la contabilidad y las audiciones de cuentas (ACA, RP, MR, vol. 642 , fols. $35 \mathrm{r}-$ Barcelona, 1354, noviembre, 22-, 36 r-Barcelona, 1354, noviembre, 26-, 37 v -Barcelona, 1354 noviembre, 26-, y 49 v - Barcelona, 1354, noviembre, 27-), así como en ápocas de recepción de pagos para su manutención (AHPB, Pere Martí, Llibre d'ápoques de l'armada contra els genovesos, fols. $9 \mathrm{r}$-Barcelona, 1354 , marzo, 31- $16 \mathrm{r}$-Barcelona, 1354, abril, $10-, 17 \mathrm{~V}-$ Barcelona, 1354, abril, 13-, 21 v-Barcelona, 1354, abril, 20- y 24 v -Barcelona, 1354, abril, 22-) o en las disposiciones para su uso como mano de obra (ACA, $R P, B G C$, vol. 2258, fol. 1 y siguientes. Barcelona, 1354 , enero, 8.).

${ }^{31}$ Las 25 galeras genovesas que azotaban la navegación catalana en el mar Tirreno se documentan en una carta escrita por Berenguer de Codinachs, maestre racional, el 30 de julio de 1354, (ACA, C, CR, Pedro III, caja 43, c. 5334. 1354, julio, 30. Sant Mateu. Regestada en L. D'ARIENZO, Carte reali, doc. 491) mientras que el 23 de septiembre ya se barajaba, en carta recibida por Arnau Selangla de un factor suyo en Pisa, la posibilidad de la llegada de una flota ligur de 25 galeras (ACA, C, CR, Pedro III, çaja 43, c. 5356. Sin data tópica, 1354, septiembre, 23. Regestada en L. D'ARIENZO, Carte reali, doc. 504).

${ }^{32}$ Conviene destacar la diferencia entre tren y línea de suministros. Se entiende por tren de suministros un convoy, formado por bestias y carros de carga, que se reclutaba junto al ejército y se movía con él, mientras que se denomina línea de suministros a una ruta de comunicaciones que unía el ejército con su base, y por la que circulaban convoyes con abastecimientos; véase Yuval Noah HARARI, Strategy and Supply in Fourteenth-Century Western European Invasion Campaigns, "The Journal of Military History" 64-2 (Abril-2000), pp. 297-333, p. 311. 
secundarias para sus intereses ${ }^{33}$, Pedro IV y Bernat de Cabrera se negaron a que unidad alguna de su flota pasara al este del estrecho de Messina ${ }^{34}$, dando a los catalanes la superioridad en el mar Tirreno pero debilitando a los venecianos en oriente. Sin embargo, el hecho de que Génova mandase el grueso de su flota de combate a aguas adriáticas no implicaba, en modo alguno, su inactividad naval ni militar en el Mediterráneo occidental.

Por un lado, las galeras genovesas no cesaron en sus acciones de castigo contra la costa catalana y los barcos de súbditos del rey de Aragón, golpeando a sus enemigos, sin excesivo riesgo y a un mínimo coste, en el que tras la rebelión judical era su punto más débil: la logística. Los catalanes trataron de repetir el éxito del verano anterior y asegurarse la superioridad en el mar Tirreno, para lo que buscaron entablar una batalla que los barcos ligures rehuyeron en todo momento ${ }^{35}$. De este modo, sin asumir demasiadas pérdidas, las galeras genovesas dañaron enormemente las comunicaciones catalanoaragonesas que unían los reinos metropolitanos de la Corona con Cerdeña ${ }^{36}$.

Por otra parte, el común de Génova no abandonó a su suerte sus plazas amenazadas en Cerdeña. Apenas Bernat de Cabrera abandonó Alguer para dirigirse a Cagliari en 1353, la ciudad se había rebelado de nuevo contra los catalanes, masacrando a la guarnición catalanoaragonesa y retomando la plaza. Alguer sería, con toda probabilidad, el objetivo prioritario del siguiente golpe descargado por el rey de Aragón ${ }^{37}$. Por ello, Génova reforzó la plaza de Alguer con un nutrido contingente de toscanos, genoveses y lombardos, que cabe

\footnotetext{
${ }^{33}$ Ya se ha mencionado la campaña de Ponç de Santa Pau en oriente, y el elevado coste en bajas -incluido el propio almirante- que tuvo la batalla del Bósforo, librada en 1352 sin ningún beneficio tangible para los intereses catalanoaragoneses; véase supra, nota 6.

${ }^{34}$ Conviene subrayar que parte importante de las galeras que la componían procedían del subsidio veneciano, véase G. Meloni, Genova e Aragona, vol. 1, p. 202, así como Andrés GIMÉNEZ SOLER, El viaje de Pedro IVá Cerdeña en 1354, "BRABLB" 5. (1909-1910), pp. 88-93, p. 90.

${ }^{35}$ PEDRO IV, Crónica, V-36.

${ }^{36}$ Innumerables noticias referidas a estos casos salpican la documentación datada en los meses de verano de 1354 , cuando los genoveses golpeaban las costas de Cataluña y todo tráfico que hallasen en el Mediterráneo occiđental. Sirven de ejemplo algunos documentos del Archivo Real de Mallorca transcritos en Guillem MORRO I VENY, La marina catalana a mitjan segle XIV, Barcelona, Museu Marítim de Barcelona, 2005, pp. 301-314. No menos ilustrativas son las provisiones para la defensa de la costa, como por ejemplo la carta escrita por Pedro el Ceremonioso a Pere Sacosta, batlle general de Catalunya ordenándole proveer "faroni fumi, alimares ac alia signa ordinata, ad tuẹdum rippariam predictam" (ACA, C, reg. 1400, fol. 82 r. Barcelona, 1354, marzo, 4) o las distintas medidas tomadas por el municipio barcelonés que, aun después de terminar la campaña en la isla, contrató caballeros que impidiesen a las galeras genovesas abastecerse de agua (AHCB, Consell de Cent, Llibre del Consell, I-19, fol. $36 \mathrm{v}$. Barcelona, 1355, septiembre 30) y armó galeras para patrullar la costa (AHCB, Consell de Cent, Llibre del Consell, I-19, fol. 44 r. Barcelona, 1355, noviembre, 21). Entre otros episodios conviene destacar el ataque a una gran nave fondeada en la playa de Barcelona, armada por mercaderes de la ciudad y fletada pộr el consejo real que residía allí. La nave ardió con toda su carga de suministros destinados al ejército regio que asediaba Alguer, lo que representó un duro reves para la logística y el día a día de las tropas del Ceremonioso. Este hecho aparece recogido, entre otras fuentes, en Francesc CARRERAS CANDI; Bartomeu GONYALONS I BOU. (eds.), Rúbriques de Bruniquer: ceremonial dels magnifichs consellers y regiment de la ciutat de Barcelona, Barcelona, Ayuntamiento de Barcelona, 1912-1916, vol. 2, p. 226.

${ }^{37} \mathrm{Si}$ bien a finales de 1353 no se podía saber dónde lanzaría Pedro IV el siguiente golpe, apenas empezó a prepararse la armada de 1354 se debió de hacer evidente el objetivo de las fụerzas regias. Los motivos de centrar los esfuerzos en Alguer, ya desde la pírricamente victoriosa campaña de 1353, fueron políticos, pero también geoestratégicos y operacionales, como se describirá más adelante.
} 
pensar que fuesen reclutados tanto en tierra del común ligur como de sus aliados visconteos $^{38}$. En la ciudad rebelde probablemente se trabajó a conciencia, durante los primeros meses de 1354, en la mejora del sistema de fortificaciones, al que se añadió un foso de considerables dimensiones ${ }^{39}$.

Sin embargo, si al principio del verano Génova no presionó con su fuerza principal en aguas del mar Tirreno, sí se empezó a tener constancia, a medida que avanzaba el otoño, del peligro de un golpe genovés contra la flota catalanoaragonesa que asediaba Alguer. Mientras tanto, en Porto Longo, en la isla de la Sapienza ${ }^{40}$, la flota genovesa obtuvo, en verano de 1354, una importante victoria naval ante la flota veneciana ${ }^{41}$. Este hecho, que en breve tiempo llevaría a la Serenísima a la firma de la paz, tuvo también entre sus consecuencias inmediatas el hecho de que Génova se halló libre para dedicar esfuerzos al teatro de operaciones del Mediterráneo occidental. Se informó al rey Pedro de Aragón de un posible plan de ataque combinado contra su armada, fijada en las labores de sitio y erosionada por ellas, por parte del ejército del juez y, simultáneamente, por mar, de una flota genovesa. No llegó a producirse; Génova, aunque victoriosa, tras una campaña como la de la Sapienza, no debía de estar en situación de afrontar un desafío semejante sin cierto tiempo de reorganización. A pesar de ello, cuando en noviembre de 1354 Alguer abría sus puertas a Pedro el Ceremonioso, en la aceptación de las condiciones de tregua por parte del rey debió de pesar, y no poco, la posibilidad de ver a su desgastada armada aislada de sus reinos por la flota genovesa y atacada por mar y tierra.

\section{b) El juez de Arborea}

Mariano IV, juez de Arborea, se convirtió en verano de 1353 en el primer objetivo estratégico de las iniciativas armadas catalanoaragonesas en Cerdeña. Sería difícil resumir aquí todo lo que el personaje representó en la política del momento ${ }^{42}$, y no corresponde a este estudio su caracterización. Sí

${ }^{38}$ Cabe destacar el contingente de lombardos, toscanos y genoveses que, según Villani, guarnecía Alguer; M. VILLANI, Istorie, p. 249. También se menciona la presencia de ballesteros
genoveses -de conocida reputación- en PEDRO IV, Crónica, V-36.

${ }^{39}$ Las dificultades de los sitiadores catalanes para tomar la plaza al asalto se debieron en buena medida a este hecho. El terreno sobre el que se asentaba la ciudad medieval, cuyo trazado murario se intuye aún hoy entre las edificaciones existentes, ofrecía no más de un tercio de su perímetro accesible por tierra, mientras que el resto da a una costa rocosa de tan difícil acceso como fácil defensa. Este hecho sin duda facilitó que los defensores reforzaran las defensas del lado de tierra firme con un hondo foso, $y$ todo el perímetro de la ciudad sobreelevando y mejorando la fortificación. Las labores de fortificación de los defensores sardos y genoveses fueron muy eficientes, como se relata en varias descripciones de las operaciones de asedio, destacando los datos de las instrucciones que Pedro IV envió, con Mateu Adriá como mensajero, a su tío y lugarteniente el infante Pedro (ACA, C, reg. 1026, fol. $115 \mathrm{v}$. Asedio de Alguer, 1354, agosto, 21 , datable por su posición en el registro). Para seguir la evolución de la fortificación de Alguer y de su perímetro véase A. CASTELLACCIO, Le fortificazioni.

${ }^{40}$ Esta pequeña isla se halla frente a la costa occidental del Peloponeso, en ruta hacia las posesiones orientales de Génova y Venecia.

${ }^{41}$ G. Meloni, Genova e Aragona, vol. 1, pp. 202-206.

${ }^{42}$ También, y es necesario destacarlo, en la historia identitaria y en la ideología de muchos historiadores sardos de la última centuria.'Sin intención de debatir el peso de este posicionamiento en algunas de las interpretaciones que han predominado en los últimos años, remito al trabajo de M.T. FERRER, La guerra d'Arborea alla fine del XIV secolo, en Giampaolo MELE (ed.), 
se debe subrayar, sin embargo, su papel protagonista en los sucesos relacionados con los episodios bélicos aquí estudiados y en el conflicto sardo, no tanto cabeza visible y catalizador de la voluntad de un pueblo como, en los aspectos políticos y técnicos de la guerra, actuando como un señor que usa sus recursos en defensa de sus intereses particulares, de su señoría y de su linaje. Mariano IV fue el blanco principal de la ejecución de justicia llevada a cabo por Pedro el Ceremonioso, para quien éste era, ante todo, un súbdito rebelde y un traidor, reo de lesa majestad ${ }^{43}$. Súbdito, sin embargo, plenamente soberano en sus tierras y potente tanto en el plano económico como en el de la política internacional y la organización militar.

Cabe preguntarse, llegados a este punto del presente estudio, cuál fue exactamente el rol de cada uno de los agentes del conflicto que estalló a fines de 1353, en el que el juez de Arborea cambió su posicionamiento y, con ello, la ecuación política y militar de los poderes que luchaban en Cerdeña. La capacidad económica y militar de la casa de Arborea, puesta frecuentemente al servicio de los reyes de Aragón, le reportaba al juez varias compensaciones; era señor de buena parte de la Cerdeña occidental y tenía otros honores feudales en el norte de la isla y en Cataluña. Sin embargo, Pedro IV y sus oficiales mantuvieron hacia Mariano IV una política de equilibrio de fuerzas, cediéndole escasas parcelas de poder ${ }^{44}$, situación que contrastaba con la debilidad militar catalanoaragonesa en Cerdeña, en gran parte dependiente de la ayuda arborense. Si las ambiciones territoriales y patrimoniales de Mariano de Arborea estaban obstaculizadas por la Corona de Aragón, Génova, tras los reveses de 1353, se

Giudicato d'Arborea e Marchesato di Oristano: proiezioni mediterranee e aspetti di storia locale. Atti del $1^{\circ}$ Convegno Internazionale di Studi. Oristano, 5-8 Dicembre 1997, Oristano, Istituto Storico Arborense per la Ricerca e la Documentazione, 2000, pp. 535-620, pp. 541-554, así como al de M. TANGHERONI, Lunghi secoli di isolamento? Note sulla storiografia sarda negli ultimi trent'anni, "Nuova Rivista Storica" 61 (1977), pp. 150-188.

${ }^{43}$ Se entenderá por rebeldes, sin la menor intención partidista y junto a los miembros de la familia Doria, a Mariano de Arborea y sus súbditos; los jueces de Arborea eran vasallos y aliados de los reyes de Aragón, tanto durante la conquista de 1323 como en años posteriores, hasta que se enfrentaron a Pedro el Cerimonioso en 1353. Esta visión jurídica y esta teoría del poder, cuyo juicio moral creo que no corresponde a la labor de un historiador, es parcial y procede de la óptica de Pedro el Ceremonioso y del reflejo de ésta en los documentos. Sin embargo, resulta de vital importancia para entender la actuación del juez de Arborea y, ante todo, de Pedro el Ceremonioso, tanto durante las tensiones previas como durante la guerra y en las negociaciones posteriores a ella. Sobre la controversia legitimista alrededor de la revuelta del juez y los derechos de Pedro IV en el Regnum Sardinie véase M. T. FERRER, La guerra d'Arborea, pp. 541-554..

${ }^{44}$ Mariano de Arborea había manifestado interés en la posesión de Alguer, ofreciéndole a Pedro IV la posibilidad de comprar la plaza a los Doria y tenerla en nombre de éste. Declaraba su intención, de este modo, de mantenerla bajo la protección del rey, en lugar de dejarla en manos de rebeldes y traidores ante un posible ataque genovés al reino (ACA, $C, C R$, Pedro III, caja 42, c. 5155. Oristano, 1353, marzo, 31. Regestado en L. D'ARIENZO, Carte reali, doc. 393). De hecho, se debe subrayar que, en la rebelión de 1353, la guarnición catalana de la ciudad fue eliminada por un ataque combinado de la población, desde dentro de las murallas, y de las tropas arborenses desde fuera, lo que supone que el juez se apoderó por fuerza de lo que Pedro de Aragón no le dio de buen grado. Algo similar puede decirse, en cierto modo, de la importantísima plaza de Bosa y de las curatorías ultra iudicatum que Mariano IV se disputaba con su hermano Juan. Pese al veredicto regio favorable a éste, Mariano IV le apresó y tuvo cautivo durante años, véase G. MELONI, Genova e Aragona, vol. 1, p. 171. Las diferencias con los oficiales regios, especialmente con el gobernador Riambau de Corbera, se relacionaban igualmente, entre otros motivos, con la abierta disputa por el control del castillo y término de Monteleone (ACA, $C, C R$, Pedro III, caja 42, c. 5225. Serravalle, 1353, noviembre, 3. Regestado en L. D'ARIENZO, Carte reali, doc. 443). 
hallaba necesitada de nuevos apoyos en Cerdeña y, gracias a su alianza con el Señor de Milán, capacitada para ganarlos a su causa ${ }^{45}$. El juez de Arborea, buscando apoyos diplomáticos y militares, juró también fidelidad a Giovanni Visconti y éste envió refuerzos a su nuevo vasallo, acompañándolos con vicarios que gobernarían Alguer y la Gallura en su nombre ${ }^{46}$.

Visto el contexto geoestratégico de mitad del siglo XIV y la integración del juez de Arborea en él, conviene detenerse sobre las capacidades militares del judicato y de su soberano. El juez de Arborea contaba, en primer lugar y como gran número de soberanos de su tiempo, con la posibilidad de movilizar a su población en caso de necesidad, bajo el mando del propio juez, pero también supervisados por la Corona de logu, asamblea estamental del judicato. Estas movilizaciones contaban con tropas de diverso tipo, en las que predominaba la infantería ligera, formadas por las gentes del territorio que servían a pie o a caballo según su poder adquisitivo ${ }^{47}$. Se organizaban según el sistema de "mutas", esto es, grupos formados por un tercio de los hombres en edad militar de una determinada circunscripción, que se alternaban semanalmente siguiendo al juez a la guerra mientras los restantes dos tercios trabajaban ${ }^{48}$. Sin embargo, debemos recordar que, en los primeros momentos de la revuelta y hasta bien entrado el verano de 1354, las principales acciones de las tropas judicales fueron eminentemente ofensivas, pues el juez salió de su territorio para atacar las posesiones catalanoaragonesas en el Sigerris y el Cagliaritano, en defensa de sus propios intereses patrimoniales y no de su territorio o de sus gentes. Por ello, Mariano IV recurrió al pago de soldadas a voluntarios, reclutados en sus tierras o en las de sus nuevos aliados genoveses y lombardos ${ }^{49}$.

\footnotetext{
${ }^{45}$ Queda constancia de una embajada genovesa enviada con este fin ante el juez de Arborea; véase G. Meloni, Genova e Aragona, voll. 1, p. 170.

${ }^{46}$ En esta relación de poderes el juez de Arborea ganaba un nuevo señor, más lejano, obligado por las circunstancias a confirmarle la posesión de feudos que el rey de Ảragón le discutía. El señor de Milán, por su parte, reforzaba su ansiada salida al mar, recién adquirida a través de Génova, con puntos vitạles de la costa sarda (y, por ello, del Mediterráneo occidental) cuya legítima posesión podía justificar y reforzar con la relación entre su linaje y los antiguos jueces de Gallura, véase G. Meloni, Alghero tra Genova, Arborea, Milano, Catalogna. Nuovi documenti, en A. MATTONE; P.SANNA, Alghero, la Catalogna, pp. 59-74. Se destaca constantemente la ayuda procedente de Milán en J. ZuRITA, Anales, VIII-55.

${ }^{47}$ Para un perfil de los ejércitos judicales, véase: Luciano GALLINARI, Una società senza cavalleria? Il Giudicato d'Arborea e la Corona di Aragona tra XIV e XV secolo "AEM" 33/2 (2003), pp. 849-879; Graziano FOIS, L'organizzazione militare nel "giudicato" d'Arborea, "Medioevo: Saggi e rassegne" 13 (1998), pp. 35-51; F. CASULA, Alghero arborense, en A. MATTONE; P. SANNA, Alghero, la Catalogna, pp. 115-124.

${ }^{48} \mathrm{~F}$. CASUlA, Alghero arborense, p. 118. Estas tropas, pese a no ser profesionales, tenían la ventaja de operar en terreno generalmente propio y con su retaguardia cerca, optimizando así, como cualquier otra milicia, las capacidades de unos hombres que estaban razonablemente familiarizados con el uso de las armas y con las prácticas guerreras de la época.

${ }^{49} \mathrm{El}$ pago de contingentes numerosos asalariados estaba perfectamente al alcance del patrimonio de Mariano de Arborea, que ostentaba el control del área cerealícola más rica de la isla -luego también de un bien estratégico y escaso susceptible de ser exportado-. Estas tropas contaban con una mayor ratio de profesionales veteranos, fáciles de hallar en las populosas y conflictivas ciudades del norte de Italia o en la propia isla de Cerdeña, azotada por los conflictos que se han señalado más arriba. Nos han llegado, por ejemplo, informes sobre hombres del juez reclutando tropas en la Toscana y en Milán para tlevarlas a Cerdeña; ACA, C,CR, Pedro III, caja 43, c. 5316 . El documento carece de datación pero, por su contenido, se adivina de mediados de mayo de 1354 .
} 
Los contingentes arborenses corrieron desde el inicio de la revuelta las tierras del rey de Aragón, cuyos oficiales se veían incapacitados para impedirlo; en este contexto el saqueo del sur de la isla no sólo debió de engrosar las arcas y reforzar los preparativos bélicos de Mariano IV, sino que debió de ser también un atractivo acicate para el reclutamiento, dadas las posibilidades de botín que ofrecía una zona tan rica como mal defendida. Si el saqueo y las perspectivas de botín podían dar lugar a la adhesión de voluntarios combatientes, no menos peso tenía la mencionada incapacidad de las fuerzas catalanas para hacerse presentes fuera de sus fortalezas; con el juez como amo indiscutido de todo el oeste y parte del sur de la isla, villas y poblaciones colaboraron con sus necesidades militares y negaron el apoyo a los oficiales catalanoaragoneses, tomando una posición que se ha interpretado como fruto de una conciencia nacional frente al invasor ${ }^{50}$. Sin descartar un componente de catalanofobia o de sentimiento identitario, este alineamiento parece mucho menos monolítico si se observan las iniciativas de los oficiales reales, que intentaron inútilmente conservar el apoyo de una población sarda más coaccionada por las fuerzas judicales que por las autoridades regias ${ }^{51}$.

Por todas las circunstancias descritas, podemos deducir que el juez de Arborea contaba con la posibilidad de movilizar potentes ejércitos, abastecerlos mediante sus propios recursos económicos, apoyarlos con maniobras diplomáticas con las repúblicas italianas y, como se verá más adelante, imponer un constante desgaste a los territorios regios y una severa amenaza a cualquier fuerza expedicionaria catalana.

\section{OBJETIVOS ESTRATÉGICOS, PLANIFICACIÓN Y DESARROLLO DE LAS OPERACIONES.}

Se debe insistir, una vez más, en el impacto que tuvo la revuelta judical sobre las opciones catalanas en Cerdeña: sin la ayuda arborense, tanto en apoyo militar como en abastecimiento, obstruída la Via Turrese por los territorios judicales, tomado por los rebeldes el principal puerto del occidente de la isla y con el otoño ya avanzado - lo que casi imposibilitaba la organización de una nueva expedición catalanoaragonesa hasta la siguiente primavera-, la revuelta

\footnotetext{
${ }^{50} \mathrm{~A}$. CASTEllaccio, Utilizzazione militare; es destacable la nota 14 de dicho trabajo.

${ }^{51}$ Cabe destacar el papel jugado por la coacción en la adhesión de toda población a un ejército; N. CovinI, Studiando, p. 236. No es casual que Bernat de Cabrera, una vez asegurada la región del Cagliaritano, tratase de recuperar la población de ésta, prohibiendo que se molestase a sus habitantes que regresaban a sus residencias (ACA $C$, reg. 1022 , fol. $38 \mathrm{v}$. Cagliari 1353 , octubre11, cit. G. MELONI, Genova e Aragona, p. 173, aunque cita el reg. como 1020 ). Es muy ilustrativa la queja de Gaddo Visconti, veguer de Fiecchi, que se lamentaba de que, por miedo a la gente del juez, jurados y villas del Ghippi y la Trexenta se comportasen como rebeldes y no entregaran sus stocks de grano a la autoridad regia (ACA, C, CR, Pedro III, caja 42, c. 5224. Sin data topica, 1353 , noviembre, 2). Bernat de Cabrera ordenaba, días después, al vicario del común de Pisa en la Trexenta que mandase a la gente de su jurisdicción a vender vituallas a Iglesias y a las curatorías vecinas de Sigeris y Sulcis $(A C A, C$, reg. 1022 , fol. 77 v. Cagliari, 1353, noviembre, 4).
} 
de Mariano IV fue un grave riesgo para las armas aragonesas, hasta el punto de poner en cuestión la posición de éstas en la isla.

\section{La ofensiva del juez y de sus aliados: Cagliari, Alguer y Sassari}

No es éste lugar para extenderse en la explicación de la revuelta judical ni para detallar sus pasos - lo que daría materia para un estudio particularizado--, pero sí es imprescindible detenerse a esbozar sus principales objetivos, y el punto hasta el que llegó su consecución.

En primer lugar, tras la victoria naval de Bernat de Cabrera frente a Alguer, la ciudad se rindió a sus armas y éste, desde ella, ejerció sus funciones de lugarteniente general en la isla durante el mes de septiembre de $1353^{52}$. En este espacio de tiempo, las fuerzas judicales se vieron incapaces de actuar en el norte de la isla, donde el contingente expedicionario aseguraba y conectaba el traspaís de Alguer y de Sassari. En el sur, sin embargo, la rebelión se hacía más manifiesta y los hombres del juez presionaban abiertamente los territorios regios. Las cartas enviadas a Bernat de Cabrera desde Cagliari expresan una acuciante preocupación, tornada en temor a perder toda posición catalana en el $\operatorname{sur}^{53}$.

El ejército del Juez de Arborea se centró en el primero de sus objetivos: conseguir el control de las plazas del sur de la isla o, si ello no era posible, desgastar al máximo el hinterland de éstas, extendiendo el control judical al área cerealícola y minera a la que, como se ha descrito, se accedía siguiendo la llanura que formaba un triángulo entre Cagliari, Iglesias y la capital arborense, Oristano. Un potente ejército de 10.000 infantes y 1000 hombres a caballo se lanzó hacia el sur, enviando el grueso de sus fuerzas hacia Cagliari ${ }^{54}$.

El capitán de guerra de Cagliari, Berenguer Carròs, trató de contener a los atacantes. Situó un contingente bajo su mando en la villa de Monastir y otro en Decimo, al mando de Gerardo, señor de la villa y conde de Donoratico. Estas fuerzas, abastecidas por las villas en que se apoyaban, podían estorbar la progresión de sus enemigos hacia el sur, cerrando el paso donde se estrecha la llanura prelitoral entre el lago y las zonas paludosas de Decimo, al suroeste, y las primeras estribaciones del macizo del Gennargentu al noreste ${ }^{55}$. Sin embargo este dispositivo, para el conde de Donoratico, implicaba la desventaja de ocupar una posición en que los pantanos protegían su flanco izquierdo pero, a la vez,

${ }^{52}$ G. Meloni, Genova e Aragona, vol. 1, pp. 169-173.

${ }^{53}$ Así se refleja en la demanda de ayuda escrita a Bernat de Cabrera por Francesc de Sant Climent, que pedía al capitán general que acudiese desde Alguer porque las fuerzas judicales amenazaban el Cagliaritano (ACA, C, CR, Pedro III, caja 42, c. 5210. Cagliari, 1353, octubre, 2. Regestada en L. D'ARIENZO, Carte reali, doc. 430).

${ }^{54}$ Joan ARMANGuÉ I HerRero; Anna CIREDdu ASTe; Caterina CuBOni, Proceso contra los Arborea, CODOIN vol. 52, Pisa, ETS, 2002, vol. 1, pp. 232-233.

${ }^{55}$ Es probable que las fuerzas pisanas derrotadas en Lucocisterna (1323) tuviesen intenciones semejantes y combatiesen en estos parajes. Véase G. MELONI, Lo stagno di Decimo e alcuni avvenimenti del Medioevo sardo-catalano. Il processo contro Gherardo di Donoratico, en Manlio BRIGAGLIA (ed.), La Sardegna, pp. 67-82, p. 68. 
difícultaban una posible retirada hacia Cagliari. El noble pisano defendía, además, su propio señorío, lo que no le inclinaba probablemente a querer verlo devastado por una batalla y saqueado. Las tropas judicales se concentraron en presionar sobre Decimo y Gerardo de Donoratico pactó con los capitanes del juez, permitió a sus súbditos que vendiesen vituallas a las tropas arborenses y abrió para éstas el camino hacia Cagliari ${ }^{56}$, obligando a Berenguer Carròs — tan incapacitado para mandarle refuerzos como indignado por su traición- a retirarse precipitadamente hacia la ciudad para no verse aislado de ella.

Las tropas catalanoaragonesas, encerradas en la fortaleza de Cagliari, veían impotentes cómo sus enemigos corrían la tierra y devastaban el hinterland de la ciudad. Los hombres del juez se llevaron cuanto grano pudieron, en carros, para concentrarlo en Monreale, y devastaron caseríos y todo tipo de instalaciones productivas, con especial atención a las salinas, fuente de renta y riqueza para la monarquía ${ }^{57}$. El capitán de guerra de la ciudad organizaba ocasionales salidas, en clara inferioridad numérica, para tratar de estorbar sus acciones ${ }^{58}$, pero los atacantes, aun rehuyendo un enfrentamiento a gran escala, tenían suficientes efectivos para conjurar esta amenaza y esparcirse por la llanura del Cagliaritano a forrajear.

Bernat de Cabrera, tras dejar una guarnición en Alguer al mando de Gispert de Castellet, embarcó su contingente y lo transportó hacia el sur. Tras enviar emisarios al juez de Arborea, al pasar frente a Oristano, llamándole a la obediencia real, el capitán general llevó su contingente hasta Cagliari, donde rápidamente lo desembarcó y lo dirigió personalmente a la batalla. Las fuerzas judicales, que probablemente debían de forrajear dispersas por un amplio espacio entre Sanluri y Cagliari, no tuvieron tiempo de reagruparse, por lo que las gentes de armas del rey de Aragón golpearon al contingente que amenazaba directamente Cagliari desde la vecina población de Quartu ${ }^{59}$. Esta batalla, probablemente, debió de ser una severa derrota para las tropas arborenses ${ }^{60}$. Con ella, las fuerzas del juez perdían su control — hasta entonces casi absoluto- del

${ }^{56}$ G. Meloni, Lo stagno di Decimo, p. 70.

${ }^{57} \mathrm{Se}$ destaca la importancia de las salinas, reservadas y cuidadas por la monarquía como regalía básica desde el momento de la conquista en M. TANGHERONI, Aspetti del commercio, p. 57-62. Destaca, para este particular, la obra de Ciro MANCA, Aspetti dell'espansione economica catalano-aragonese nel Mediterraneo occidentale : il commercio internazionale del sale, Milán, A. Giuffrè, 1965 .

${ }^{58}$ Véase infra, nota 59.

${ }^{59}$ Cabe destacar que cualquier operación de castigo o saqueo exige dispersar geográficamente las fuerzas para optịmizar el radio de acción y de captaciọn de recursos. Esto, sin embargo, sólo podía hacerse en situación de ventaja o lejos del enemigo, pues, si éste presentaba batalla al ejército que forrajeaba, había grave riesgo de que causase estragos en las unidades dispersas antes de que pudieran reagruparșe. Este fue, probablemente, el caso de la batalla de Quartú. Sobre la dispersión y la concentración de los ejércitos para moverse, forrajear y combatir, véase $\mathrm{Y}$. $\mathrm{N}$. HARARI, Strategy, pp. 306-310.

${ }^{60} \mathrm{Las}$ fuentes aragonesas parecen apuntar en esta dirección, pero se plantean algunas dudas al respecto en G. MELONI, Genova e Aragona, vol. 1 pp. 172-173, a raíz de las referencias aparecidas en la crónica de M. VILLANI, Istorie. Todo indica que el resultado de la batalla contribuyó a estabilizar la situación en el sur, ya que la documentación expedida desde Cagliari por Bernat de Cabrera deja de centrarse en las fuerzas arborenses que antes de la batalla la copaban. El propio vizconde de Cabrera explica detalladamente su victoria en una carta escrita en Cagliari noviembre de 1353 (ACA, C, reg. 1022, fol. 50 v. y siguientes. Cagliari, 1353, noviembre, 2.). 
sur de la isla y la ventaja de ser un ejército invicto ${ }^{61}$; si bien no quedaron inactivas y estaban lejos de ser completamente derrotadas, la posición de las armas aragonesas alrededor de Cagliari quedaba estabilizada y a salvo, tras un momento de grave riesgo ${ }^{62}$.

Sin embargo, mientras el contingente expedicionario mandado por el vizconde de Cabrera aseguraba su situación en el Cagliaritano, la ciudad de Alguer, guarnecida por una nutrida compañía de hombres del rey, sufrió un ataque por parte de tropas arborenses y genovesas, combinado con un levantamiento armado dentro de la ciudad. Las tropas que defendían las fortificaciones, atrapadas entre dos frentes, fueron derrotadas de forma rápida y expeditiva, de modo que los supervivientes apenas pudieron abandonar la ciudad embarcando en galeras o alcanzando Sassari.

Con esta acción el juez de Arborea conseguía, aunque renunciando a su pretensión de tomar Alguer, un importante triunfo al entregar la ciudad a su nuevo señor, Giovanni Visconti, aislar Sassari de una de las mejores posiciones fortificadas del noreste de la isla y, además, conectar cómodamente sus territorios con los de sus aliados Doria de la Gallura. Tanto se comprometió la posición catalana en el norte que Sassari llegó a encontrarse de nuevo bajo asedio, y sólo pudo mantenerse inexpugnada gracias a los refuerzos enviados por Bernat de Cabrera, desde Cagliari y en ocho galeras, que consiguieron desembarcar en Porto Torres y entrar a Sassari a reforzar la guarnición que mandaba el gobernador Riambau de Corbera. Éste, sin embargo, apenas pudo apoyar a sus hombres en las fortalezas que protegían los aproches de Sassari y su comunicación con el mar; así, Castelgenovese caía en manos de los Doria.

De este modo, la señoría de Pedro el Ceremonioso perdía todas las ventajas territoriales y geoestratégicas conseguidas alrededor del estrecho de Bonifacio y el Logudor durante la hábil, infructuosa y costosísima campaña capitaneada por Bernat de Cabrera en el verano de 1353. El capitán general regresó a los reinos metropolitanos de Pedro IV y éste le recibió con grandes honores; es muy probable que, mientras celebraban los triunfos de Porto Conte y Quartu y la salvación de Cagliari, el rey y su privado planeasen el envío de una poderosa armada, planteada como una segunda y definitiva expedición de conquista.

\footnotetext{
${ }^{61}$ Era importante, para todo contingente, ser la única fuerza visible desplegada alrededor de las vías principales y capaz de ofrecer a sus gentes de armas opciones de saqueo y botín, con todo lo que eflo implicaba para la moral de la tropa y para la adhesión de la población no combatiente. La visibilidad de un ejército también era de gran importancia -ante todo en caminos y poblaciones importantes- ya que potenciaba la sensación de control de la situación, el prestigio de sus jefes y la adhesión de la población. Véanse las excelentes reflexiones sobre estos particulares de N. Covini, Studiando, p. 252.

${ }^{62}$ Así seguiría en años sucesivos, para convertirse en bastión inexpugnable hasta la definitiva conquista de la isla en la centuria siguiente. Bernat de Cabrera reforzo las guarniciones de varios castillos y de la propia Cagliari, asegurando la situación cuando el otoño estaba demasiado cerca para que las fuerzas jụdicales pensaran en preparar un nuevo ataque a gran escala en el sur. Como medidas extraordinarias para sostener el esfuerzo bélico, ordeno confiscaciones de paños, grano y esclavos, que se vendieron en el mercado de Cagliari para obtener dinero con que pagar a las tropas, como se registró, años después, en una audición de cuentas de la armada de 1353 (ACA, $R P, M R$, vol. 642, fol. 312 r. Zaragoza, 1357, febrero, 24).
} 


\section{Buscando una ejecución de justicia definitiva: La expedición regia de 1354.}

En diciembre de 1353, tratando de recobrar la iniciativa en Cerdeña y de eliminar la constante inestabilidad de sus dominios en la isla, rey decidió pasar a ella en persona, en primavera del año siguiente, al mando de una potente armada, buscando la definitiva sujeción de los rebeldes sardos y Doria, la expulsión de los intrusos genoveses y el control de los territorios de la isla ${ }^{63}$.

El rey buscó todas las fuentes posibles de financiación y métodos de organización para la campaña, que se tradujeron en un complejo sistema fiscal y administrativo. Sin que sea posible detenerse aquí sobre estos particulares - algunos de los cuales han sido extensamente estudiados - conviene señalar la armada de Pedro el Ceremonioso a Cerdeña como un enorme esfuerzo militar catalanoaragonés, pero también como impulso de un complejo sistema de obtención y gestión de recursos económicos, políticos y militares ${ }^{64}$.

La gran campaña del verano debía ser precedida por una pequeña fuerza expedicionaria, mandada por Miguel Pérez Zapata, que se compondría de 6 galeras y 6 ujieres, que escoltarían y transportarían 80 caballos armados, 20 a la jineta y 500 infantes $^{65}$. Esta avanzada perseguía un doble propósito: debía

\footnotetext{
${ }^{63}$ Los hechos de la expedición y de su contexto inmediato pueden seguirse fácilmente en varias obras coetáneas; destacan la propia crónica del soberano PEDRO IV, Crónica, V, 31-43, así como los Anales de Aragón de Zurita (J. ZURITA, Anales, VIIÎ-53 a 55) y otras fuentes cronísticas (M. VILLANI, Storie, XXI y XXXIV). Existen varios trabajos, más o menos recientes, que sintetizan los sucesos de la campaña; véanse principalmente G. MELONI, Genova e Aragona, vol. 1, pp. 181-213; IDEM, Alghero; F. CASULA, Alghero arborense; IDEM, La Sardenya catalanoaragonesa, pp. 43-47. También, pese a ser una aportación más antigua, resulta interesante el trabajo de Arrigo SolmI, Studi storici sulle istituzioni della Sardegna del medioevo, Nuoro, Ilisso Edizioni, 2001 (Reedición a cargo de Maria Eugenia CADEDDU), pp. 403-409. Hay que destacar algunos detalles de gran interés en A. GIMÉNEZ SOLER, El viaje, pp. 88-93.

${ }^{64}$ Éste fue un paso de gran importancia, conectado con las campañas anteriores y la posterior guerra con Castilla, para configurar el perfil del sistema impositivo y burocrático que, orbitando ălrededor de la guerra, marcaria durante siglos el sistema político de la señoría del rey de Aragón. Para la búsqueda de financiación destinada a esta campaña véase G. MELONI, Genova e Aragona, vol. 1, p. 185. El desarrollo de la fiscalidad real y de los distintos sistemas de gestionar imposiciones y deuda pública por parte de las distintas instituciones reales, nobiliarias eclesiásticas y municipales ha dado lugar a una amplia historiografía. Sin intención ni posibilidad de resumirla aquí, sụ relación con las campañas sardas y la organización militar durante "el siglo XIV tiene su reflejo en numerosas obras. Véanse, por ejemplo, M. SÁNCHEZ, "Corts", "parlaments" y fiscalidad en Cataluña: las "profertes" para las guerras mediterráneas (1350' 1356), en M. SÁNCHEZ, Pagar al rey en la Corona de Aragón durante el siglo XIV, Barcelona, Institución Milà i Fontanals-Departamento de Estudios Medievales-CSIC, 2003, pp. 291-313 IDEM, Las cortes de Cataluña en la guerra de Arborea, en M.T. FERRER; Josefina MUTGÉ I VIVES; M. SÁNCHEZ, (eds.) La corona catalanoaragonesa i el seu entorn mediterrani a la Baixa Edat Mitjana. Barcelona, Institució Milà i Fontanals-Departament d'Estudis Medievals-CSIC, 2005, pp. 363-393. Véase también P. ORTI; M. SÁNCHEZ (eds.), Corts, parlaments $i$ fiscalitat a Catalunya: els capitols del donatiu (1288-1384), Barcelona, Generalitat de CatalunyaDepartament de Justícia, 1997, pp. 108-156; Prim BERTRAN I ROIGÉ, Notes sobre els subsidis de l'Es glésia catalana per a la guerra de Sardenya (1354), "AEM", 29 (1999), pp. 121-140. No tan desarrollado se halla el estudio de los distintos entramados institucionales asociados a las armadas y ejércitos regios pero, aun así, la armada referida aquí cuenta con excepcionales trabajos que ayudan a comprender parte de su única y excepcional configuración administrativa. Cabe destacar aquí el excelente estudio de la Dra. Alexandra Beauchamp, a quien debo agradecer el acceso al manuscrito de su tesis doctoral; véase Alexandra BEAUCHAMP, Gouverner la Couronne d'Aragon en l'absence du roi: la lieutenance générale de l'infant Pierre d'Aragon (1354-1355), tesis doctoral inédita.

${ }^{65} \mathrm{ACA}, \mathrm{C}$, reg. 1398, fol. 19 v. Barcelona, 1353, diciembre, 27.
} 
contribuir a reforzar las posiciones catalanas en la isla y, ante todo, empezar las hostilidades al despuntar la primavera, corriendo la tierra del juez de Arborea y desgastándola económicamente antes de la época de siega y recolección ${ }^{66}$. La flota principal debía partir a mitad del mes de abril ${ }^{67}$, sin embargo la realidad de una campaña de tan grandes dimensiones no podía amoldarse a las dificultades inherentes al reclutamiento, al transporte y a la logística, por lo que al fin partió de Rosas el 15 de junio de 1354. Conviene subrayar este hecho, aparentemente secundario, como un inconveniente de primera magnitud para la buena marcha de la campaña: gran parte de los suministros reunidos para la armada se consumieron antes de que ésta pudiese comenzar a operar. Algo semejante ocurría con un elemento tan preciado como el tiempo; éste, que en la guerra solía correr a favor del defensor, se escapaba de las manos de Pedro el Ceremonioso, dificultando la consecución de sus objetivos ${ }^{68}$.

La "armada e viatge" 69 de Pedro el Ceremonioso estaba posiblemente compuesta, en primer lugar, por una flota de unas 100 embarcaciones de buen porte, tanto de guerra como de transporte, así como un gran número de buques menores, tripulados por unas 11.000 personas $^{70}$; esta flota pudo transportar,

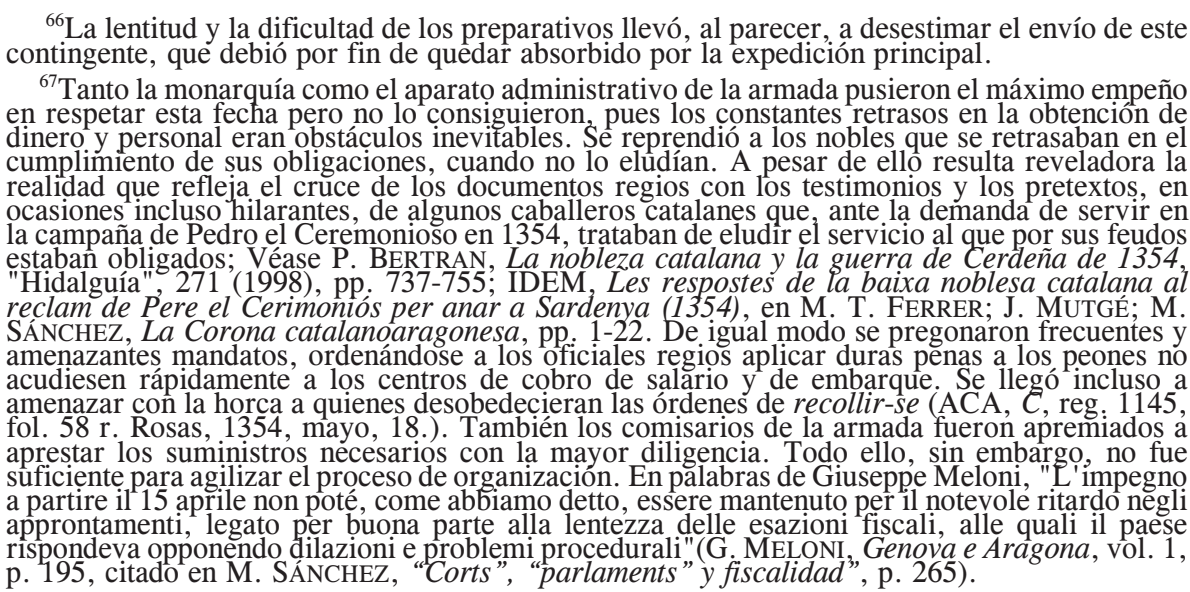

${ }^{68}$ En un contexto en que las guerras, la producción económica y la naṿegación sufrían fuertes variaciones estacionales, resultaba prioritario iniciar las campañas ofensivas en primavera, para optimizar sus resultados antes de que las lluvias y el frío del otoño dificultasen o impidiesen el desarrollo de las operaciones. En el mismo mes de abril, además, Iglesias, una de las plazas principales de la isla, se rebelaba obligando a la guarnición catalana a refugiarse en el castillo $(\mathrm{G}$. Meloni, Genova e Aragona, vol. 1, p. 198).

${ }^{69}$ Éstos son los términos habituales utilizados por la administración regia para designar la campaña. Hay que subrayar que la palabra armada designa toda la expedición, esto es, un ejército apoyado por un dispositivo naval de transporte y combate. Todo ello, además, estaba dotado de un aparâto administrativo, económico y logístico propio. La referencia al viatge se debe a la presencia de la persona del rey, que viaja con la expedición.

${ }^{70}$ Resulta orientativo el número de 40 galeras y 20 naves para la flota de combate (ACA, $C$, reg. 1400, fol. 3 r. Barcelona, 1354, enero, 10) más sostenible al cruzarlo con otras evidencias que el de 60 galeras ( ACA, C, reg. 1400, fol. 21 r. Barcelona, 1354, enero, 18), pero queda oscurecido por lo sesgado de los testimonios documentales, que apenas recogen noticias de los numerosísimos barcos de particulares que fueron requisados y añadidos a la flota, alcanzando o superando las cien velas. Para una aproximación parcial a las cifras de la flota, sus barcos y los efectivos transportados, véase Mario ORSI LÁZARO, Les dotacions dels vaixells de l'armada de 
según las previsiones iniciales, cerca de 1.000 caballos armados, 500 a la jineta y 10.000 peones o soldados de infanteria, lo cual podría traducirse en unos 15.000 hombres y 3.000 monturas $^{71}$.

\section{a) Planes iniciales hacia una victoria decisiva: el intento de combate naval y de ataque a Oristano}

Ya se ha señalado la intención de Pedro el Ceremonioso de acabar, en la expedición de 1354, con la problemática sarda de un solo golpe, castigando a rebeldes e intrusos de modo definitivo; así se ha afirmado muchas veces en la historiografía referente al tema, y no sin razón ${ }^{72}$. Sin embargo, llegados a este punto, debemos preguntarnos si esto era posible o, mejor aún, si el rey y sus consejeros militares y políticos lo consideraban factible, y cómo, llegado el caso, esto influyó en su planificación ${ }^{73}$.

No parece descabellado pensar que, en parte, las intenciones manifestadas en la documentación regia estuviesen dirigidas a conseguir el apoyo de los estamentos de los distintos reinos de la corona. Pese al constante intento de la

1354: motivacions, context social i costos humans, "Drassana", 15 (2007), pp. 54-73.

${ }^{71}$ Respecto a las tropas de tierra, hay que tener en cuenta que los "cavalls armats" y los "cavalls alforrats" o a la jineta son unidades administrativas y contables para el reclutamientọ. En cualquier caso, contando el caballo armado como 4 hombres y 2 monturas, el caballo a la jineta como 2 hombres y una montura (M. T. FERRER, La organización militar, pp. 169-173) y los peones como unidades individuales, podríamos estar hablando de un ejército de unos 15.000 hombres y 3.000 caballos. Resulta imposible, dada la variedad y las diferencias existentes entre los distintos testimonios, hablar de cifras exactas en el aspecto de los efectivos y medios movilizados, pues hay que recordar que la diversidad de fọmas de reclutamiento obligatorio o asalariado, desde la iniciativa de la monarquía hasta las comitivas de nobles y caballeros, dificulta o imposibilita un cómputo exacto de los efectivos. Existen evidencias de la documentación generada con anterioridad a otras campañas para hacer las previsiones y planes de éstas, véase, para el caso de la conquista de Cerdeña en 1323, Antonio ARRIBAS PALAU, La conquista de Cerdeña por Jaime II de Aragón. Barcelona, Instituto de Estudios Mediterráneos, 1952, pp. 377 379. Sin embargo, las cifras para la campaña de 1354, recurrentes en las cartas escritas por orden del rey, deben ser tomadas como referencias orientativas, basadas en una previsión aproximada y, probablemente, magnificadas por la voluntad de afirmación del poder real ante los destinatarios de sus documentos.

${ }^{72}$ M. SÁNCHEZ, “Corts”, “parlaments” y fiscalidad, pp. 291-313.

${ }^{73}$ La idea de la "victoria decisiva" ha quedado tan arraigada en la historiografía de la guerra, tantos debates y matices ha generado a causa de su dosis de presentismo, que merece la pena detenerse brevemente sobre ella. Concepto actual pero no poco anacrónico, de difícil aplicación al contexto politicomilitar del siglo XIV, su formulación teórica es de aparición tardía, decimonónica, por más que con frecuencia se ve aplicada a la historia medieval. Véase el excelente trabajo de Francisco García Fitz sobre las Navas de Tolosa, donde hace un exhaustivo seguimiento de las diversas estrategias aplicadas por los castellanos antes y después de la batalla, en las que ésta tiene un valor indudable pero no determinante (Francisco GARCíA FITZ, Las Navas de Tolosa, Barcelona, Ariel, 2005, especialmente el capítulo II, pp. 59-100). Las opiniones de Garcia Fitz respecto a las "batallas decisivas" parecen aplicables al caso sardo; buscar una gran victoria en batalla era arriesgado $y$, aun en caso de resultado favorable, costoso en bajas. Resultaba, a largo plazo, menos eficiente que el uso de una presión constante y de coste y riesgo relativamente menores, orientada al desgaste y al agotamiento económico del enemigo. Su reflexión en torno a estos aspectos es heredera de algunos estudios, ya clásicos, como por ejemplo los de Raymond C. SMAIL, Crusading warfare, 1097-1193, Cambridge, Cambridge University Press, 1967, especialmente pp. 138-203 o, principalmente, John GILLINGHAM, Richard I and the science of war in the Middle Ages, en John FRANCE, Medieval Warfare 1000-1300, Hampshire, Ashgate, 2001 pp. 299-312. Sin embargo, se sabe que Pedro IV tendía, al parecer, a creer en una cierta posibilidad de alcanzar victorias decisivas, ante todo a causa de su escasa capacidad de mantener ejércitos en servicio durante demasiado tiempo; véase M. T. FERRER, La organización militar, pp. 199-200. 
monarquía de mantener tropas en Cerdeña de modo estable, mediante la infeudación de señoríos o la franquicia de población a cambio de servicio militar $^{74}$, Pedro el Ceremonioso sólo podía contar con contingentes de cierto volumen a través del pago de salarios a profesionales que, procedentes de los reinos metropolitanos, operaban en territorio sardo durante poco tiempo, generando un gasto considerable y sostenidos por una complicada logística que la rebelión arborense dificultaba aún más ${ }^{75}$.

Esta situación favorecía a los enemigos de Pedro el Ceremonioso en Cerdeña. El rey se hallaba limitado por su capacidad, basada en pequeñas guarniciones que defendían los puntos clave del territorio y en la presencia de fuerzas expedicionarias, potentes pero incapaces de servir de modo no ya permanente, sino ni siquiera continuo. Los enemigos de Pedro IV podían prever la dinámica que seguía a cada uno de sus ataques a la corona, conocer el operativo preparado por las armas regias y, si era necesario, pactar una tregua o una submisión temporal, cuya ruptura el rey, una vez desmovilizada cada armada, difícilmente podía castigar. Aun en el caso de una expedición victoriosa como la de Bernat de Cabrera en 1353, las fuerzas catalanoaragonesas no podían explotar fácilmente la victoria; cualquier intento de operar tierra adentro dificultaba el aprovisionamiento y alargaba el tiempo de servicio de la tropa, hasta hacer imposible el sostenimiento de una presión suficiente por parte de las fuerzas de Pedro IV. Sardos y genoveses, como se verá más adelante, lograban contener las represalias regias con sólo defender sus puntos fuertes durante el tiempo suficiente.

El perfil que se acaba de trazar hacía necesario, para justificar cada expedición ante propios y extraños, que el rey la plantease como una campaña de la mayor importancia ${ }^{76}$. Probablemente, pues, tratando de obtener batallas y victorias "decisivas" para aumentar la frecuencia y la cuantía de las ayudas

\footnotetext{
${ }^{74}$ Es el caso de los feudos concedidos por Pedro IV a Manfredo y Matteo Doria a cambio de servirle con veinte caballos ạmados durante tres meses al año, (G. MELONI, Genova e. Aragona, vol. 1, p. 154). Hay evidencias aún más claras del intento de aplicar este sistema. En primer lugar puede verse en las concesiones para la repoblación de Alguer tras la conquista (Sirvá de ejemplo la que se halla en ACA, C, reg. 1024 , fol. 68 r. Alguer, 1354, diciembre, 8), pero ante todo en la exhaustiva lista de caballeros obligados a servir al rey por sus feudos, recogida en el mal llamado "repartimiento" de Cerdeña de 1358; véase Próspero de BOFARULL Y MASCARÓ, Repartimientos de los reinos de Mallorca, Valencia y Cerdeña, CODOIN, 11, Barcelona, Imprenta del Archivo Real, 1856, pp. 856-859.

${ }^{75}$ En ese contexto, cabe recordar que cada reino de la Corona de Aragón contaba con cierta capacidad armada que, a través de las distintas obligaciones militares, el rey podía movilizar para fines defensivos; sin embargo, el patrimonio real y la capacidad exactiva de la monarquía no le alçanzaban para mantener por su cuenta una política exterior agresiva, y las aportaciones de cada reino a las guerras "privadas" del rey debian negociarse en unas asambleas estamentales no siempre dispuestas a colaborar o, en cualquier caso, capaces de cobrar un precio político por su ayuda. Véase, para la diferenciación conceptual entre ejércitos ofensivos y defensivos, de los reinos y del rey, J. SÁIz, La organización militar, pp. 738-740.

${ }^{76}$ Los discursos reales planteados ante cortes y parlamentos nos hablan de un constante hincapié en los aspectos de la legitimidad de la señoría del rey y de la perfidia de sus vasallos rebeldes, pero también, de modo más secundariọ, en la voluntad de solucionar el problema, presentando cada dẹmanda de ayuda como necesarià y definitiva. Véase M. SÁNCHEZ, Las cortes de Cataluña, especialmente pp. 364-384; Suzanne F. CAWSEY, King Pedro IV of Aragon, royal propaganda and the tradition of royal speechwriting, "Journal of Medieval History" $25-4$ (1999), pp. 357-372. Pese a todo, las cortes y parlamentos de los distintos reinos, particularmente de Cataluña, dejaron de financiar la presencia militar en Cerdeña a medida que avanzaba la centuria; véase M. SÂNCHEZ, Las cortes de Cataluña, pp. 382-394.
} 
económicas, ante la imposibilidad de planificar soluciones a medio o largo plazo. En realidad, la intención de buscar la victoria en una sola campaña tal vez reflejase la incapacidad de la monarquía para mantener una presencia militar fuerte y constante en el Regnum Sardinie.

Sin embargo, por extraña que pueda parecer la posibilidad de pacificar Cerdeña con una sola "batalla decisiva", conviene recordar que, desde la óptica del rey de Aragón y de sus fieles, la campaña de 1354 se veía como una ejecución de justicia contra un rebelde (Mariano de Arborea) y sus aliados y enemigos públicos (Génova y, en menor medida, el señor de Milán), por lo que el problema podría solucionarse cuando Mariano IV cayese en manos de la justicia real y pagase por su felonía ${ }^{77}$. Tras esta reflexión, podríamos decir que Pedro el Ceremonioso buscaba en 1354 una victoria decisiva por varios motivos. En primer lugar, porque había conseguido no pocas en los años anteriores $^{78}$. También, en buena medida, porque consideraba parte del conflicto sardo como una violación de la lealtad personal a él debida por el juez de Arborea y, por lo tanto, a éste como el principal problema a eliminar, sin atender a otra prioridad ${ }^{79}$. Por último, conociendo las capacidades y la disponibilidad de recursos que el rey y sus reinos podían aplicar al problema sardo, cabe decir que no tenían demasiadas alternativas para escoger.

Con este plan de operaciones, destinado a propiciar una campaña rápida y ejemplarizante, la flota de Pedro el Ceremonioso arribó a Porto Conte, donde desembarcó a las tropas de tierra. Tras un día de reposo, por mar y por tierra, las fuerzas regias desfilaron ostentosamente ante Alguer, uniéndose al gobernador

\footnotetext{
${ }^{77}$ Podría decirse, en última instancia, que desde la óptica regia se percibía un problema de lealtad personal, que terminaba cuando el traidor recibía su castigo; hay varios procesos publicados en la CODOIN, contra el rey de Mallorca -vols. 29-31-, contra los Arborea -vols. 51 y 52- y contra Bernat de Cabrera -vols. 32-34- que son una muestra clara del concepto de poder y lealtad del Ceremonioso. Por todo ello, el control del territorio y de sus puntos clave eran, en parte, un medio además de un fin, y la persona del juez era un objetivo prioritario en sí misma.

${ }^{78} \mathrm{~A}$ ojos del rey, si la ejecución acababa con la captura y el proceso del rebelde, tal vez Cerdeña podría quedar tan pacificada como quedó Aragón tras la victoria realista de Epila o Mallorca después de la de Llucmajor, que cerraron conflictos de modo definitivo. Pedro el Ceremonioso parecía tener intención de actuar como en las anteriores ejecuciones, confiando en su legitimidad y en la superioridad de su ejército de maniobra. Las referencias son constantes en las letras enviadas por el monarca: "... dins breus dies, mitjancant Nostre Senyor Déu, serem aquí ab tal e ten gran poder que axí la vila d'Esgleyes com tots los altres lochs a nos rebel-lats en Sardenya subjugarem a nós e reintegrarem a nostre dret e a nostra senyoria."; ACA, $C$, reg. 1023, fol. 45 r. Playa de Barcelona, 1354 , mayo, 5 . También destaca la potencia de la armada que prepara en una carta escrita a Luis de Sicilia (ẢCA, C, reg. 1400, fol. 21 r. Barcelona, 1354, enero, 18).

${ }^{79}$ No debió de ser casual que Pedro Martínez de Luna, cuando dirigió la desdichada armada de 1368 contra los Arborea -cabe pensar que siguiendo instrucciones del rey-, sobrepasase de noche los castillos que protegían y circundaban Oristano para atacar directamente la capital judical. La expedición termino con una aplastante victoria judical que en poco tiempo redundaría en la caída de Sassari. El asalto a las murallas, una vez más, fracasó. Las guarniciones de las fortalezas cercanas se agruparon y atacaron por la retaguardia el campamento de los catalanes que, atrapados entre este ataque y la salida de la guarnición de Oristano fueron aniquilados sin opciones de retirada; F. CASULA, La Sardenya catalano-aragonesa, pp. 49-51. Cabe destacar que en 1354 Pedro IV sufrió, como se verá, una situación similar -con el enemigo cerca, ante una fortaleza y lejos de territorio amigo-, ante la que optó por pactar la rendición de Alguer a cambio de una paz desfavorable. Para los pactos que cerraron el sitio de Alguer véase L. D ARIENZO, La pace di Alghero stipulata tra l'Aragona e l'Arborea nel 1354, en AA. VV, Medioevo. Età moderna. Saggi in onore del proff. Alberto Boscolo, Cagliari, Sarda Fossataro, 1972. p. 119 -148
} 
Riambau de Corbera en el sitio y bloqueo de ésta. Mientras la flota bloqueaba la ciudad y aseguraba las comunicaciones y el aprovisionamiento de la armada por mar, las tropas de tierra atacaron la fortaleza. El siguiente paso, tras controlar Alguer, era avanzar hacia el Campidano, con intención de tomar Bosa y atacar inmediatamente Oristano, la capital judical.

La posesión de Alguer, como se ha señalado más arriba, resultaba básica, pues era el primer escalón logístico y operacional, tanto para enlazar con Sassari como para maniobrar hacia Oristano; tomarlo en el primer momento hubiese supuesto, para el contingente regio, el acceso a un puerto seguro ${ }^{80}$. Dirigiendo el primer golpe contra Alguer, aprovechando la superioridad numérica, los catalanes planeaban tomar la plaza al asalto, después de abrir brecha en la muralla con la maquinaria de asedio. Algo semejante buscaban hacer las fuerzas regias en el mar, lanzando la flota de combate contra la escuadra de galeras genovesas que guarnecía las aguas de Alguer y que en ese momento estaba, como ya se ha dicho, en situación de clara inferioridad. La experiencia del año anterior, en el que, como se decía en la crónica regia, con ganar el mar se tomó la ciudad ${ }^{81}$, empujó a la flota de Pedro IV a buscar un nuevo y decisivo choque, con la esperanza de estrechar aún más a los defensores de Alguer.

Sin embargo, la realidad de la guerra en el contexto de esta campaña era, como es bien sabido, poco favorable a los planes de la hueste regia. Las fortificaciones de la ciudad, la reforzada guarnición y los preparativos aprestados durante el invierno daban a los defensores una ventaja, tanto táctica como estratégica, difícil de superar en un asalto frontal. Las fuerzas navales genovesas rehuyeron el combate directo $^{82}$ — para el que se hallaban en clara desventaja - y se dispersaron, dispuestas a hostigar la línea de suministros que, sin duda, necesitaría el potente ejército de Pedro el Ceremonioso para sobrevivir en terreno enemigo. Así daba comienzo un largo sitio, en el que las fuerzas de Pedro el Ceremonioso se consumirían y menguarían durante casi seis meses, desgastándose impotentes ante la ciudad de Alguer.

${ }^{80}$ Esto se debía, en primer lugar, a su ya mencionada condición de puerto natural y a su potente fortificación. También, sin embargo, a su relativa lejanía de las plazas, como Bonifacio o Castelgenovese, que cerraban el estrecho de Bonifacio y servían de bases genovesas, desde donde se podía hostigar otros fondeaderos menores en poder de las armas regias, como Porto Torres. A todo ello conviene añadir que, si el puerto alguerés servía para garantizar la logística ofensiva del rey de Aragón, no menos importante era su posible función de refugio, tan dificil de expugnar como bien comunicado, en caso de una hipotética retirada catalana desde los territorios judicales. Esta hubiese sido casi imposible desde el Campidano hacia Sassari, tanto por la lejanía de ambos puntos como por la amenaza, a lo largo del camino, de los feudatarios rebeldes filogenoveses. La posibilidad de atacar Oristano directamente desde Sassari quedaba, pues, descartada, ya que Porto Torres era menos apropiado como puerto logístico catalanoaragonés y Alguer, en manos del señor de Milán, hubiese sido uno óptimo para comunicar a los rebeldes con Gênova, además de una grave amenaza en el flanco occidental de Sassari y de la ruta que, siguiendo la Via Turrese, hubiese sido el eje del ataque principal contra Bosa y Oristano.

81 "Un gentilhom de Gènova, qui era pres en la galera del dit capità nostre, dix: "Misser, no et cal aparellar batalla, que, pus que ets senyor de la mar, sic seràs de la terra"; PEDRO IV, Crónica, V-21.

${ }^{82}$ Pedro IV, Crónica, V-36. Véase supra, nota 35. 


\section{b) El reflejo obsidional: el Sitio de Alguer}

Pese a los planes de Pedro el Ceremonioso, la realidad de la guerra en el occidente bajomedieval tendía a perjudicar cualquier intento de campaña ofensiva de maniobra, otorgando la ventaja a quien defendiese una fortaleza. Se sabe que las acciones solían orientarse a atacar o defender puntos fortificados, o bien a saquear o proteger el territorio circundante. Esta estrategia, conocida como reflejo obsidional ${ }^{83}$, marcó las formas de hacer la guerra del occidente bajomedieval europeo y mediterráneo, y la isla de Cerdeña no fue una excepción. Ante el ataque del Ceremonioso en 1354, Alguer resistió y los asaltos, costosísimos en bajas, se sucedieron sin éxito, cosa que obligó a Pedro IV y a su ejército a mantenerla asediada ${ }^{84}$.

\footnotetext{
${ }^{83}$ Los limitados medios materiales de los poderes de la época y de sus ejércitos - desde el punto de vista tecnológico, logístico demográfico y económico- no permitían desarrollar dispositivos que diesen ventaja a quienes querían asaltar una fortaleza; véase Bernard S. BACHRACH, Medieval Siege Warfare: a Reconaissance, "The Journal of Military History", 58-1 (Enero-1994)pp. 119133. Sin embargo, las técnicas constructivas permitían dársela, con mucho, a quien dispusiese de una fortificación y se encerrase en ella con reserva de hombres y provisiones, cosa que hacía cualquier comunidad que sufría un ataque. Esta situación recibió el nombre de reflejo obsidional, concepto básico para entender el funcionamiento de la guerra en el occidente medieval europeo, acuñado en su estudio sobre la guerra en el principado de Lieja por Claude GAIER, Art et organisation militaires, pp. 40-46, y 204-217. Conviene también señalar el uso del concepto, para definir las realidades del norte de Italia, por Aldo A. Settia: “... il valore difensivo è, in generale tecnicamente basso, ma viene esaltato dalla limitatezza dei mezzi a disposizione degli attaccanti..."; véase A. SETTIA, Rapine, assedi, battaglie, p. 83 . Por último, para el ámbito peninsular, conviene subrayar la aportación de F. GARCÍA FITZ, El reflejo obsidional y su plasmación en la normativa medieval castellano-leonesa de la plena Edad Media, en Francisco TORO CEBALLOS, José RODRÍGUEZ MoLINA (eds.), III Estudios de frontera: Convivencia, defensa y comunicación en la frontera: congreso celebrado en Alcalá la Real el 18 al 20 de nov. de 1999 Jaén, Diputación Provincial de Jaén, 1999, pp. 269-292; IDEM Castilla y León frente al Islam: estrategias de expansión y tácticas milltares (siglos XI-XIII), Sevilla, Secretariado de Publicaciones de la Universidad de Sevilla, 1998, pp. 171-176. Debo y agradezco buena parte de las referencias de esta nota al propio Dr. García Fitz.

${ }^{84}$ Las circunstancias del asedio, descritas en los sucesivos párrafos, pueden seguirse en los documentos publicados en A. GIMÉNEZ SOLER, El viaje,pp. 89-92; Ramon GUBERN Epistolari de Pere III, Barcelona, Barcino, 1955, 2 vols, vol. 1, p. 115, así como en las fuentes cronísticas anotadas anteriormente (véase supra, nota 63). El enorme dispositivo de asedio desplegado fue insuficiente y los sitiadores sufrieron, además, numerosas bajas, causadas por las salidas efectuadas por los defensores (ACA, $C$, reg. 1026, fol. 106 r. Asedio de Alguer, 1354, agosto, 4.). Las cronicas refieren con gran detalle los avatares del asedio, pero su visión, por motivos obvios, resulta considerablemente incompleta y sesgada. Sin embargo, complementándolas entre sí y cruzándolas con las informaciones procẹdentes de la cancillería regia, se puede trazar un retrato claro de las circunstancias tácticas, técnicas y logísticas que rodearon el sitio, con una abundancia descriptiva que, sólo por la acumulación de datos, excedería el presente estudio. Periódicamente, el monarca escribía a su tío Pedro -conde de Ribagorza y de las montañas de Prades y lugarteniente general en los reinos citramarinos- y a distintas autoridades y fuerzas vivas de sus reinos, informándoles de la marcha de la campaña y pidiendo refuerzos y apoyo económico y material. En ellas se pueden contemplar aspectos de la campaña que contrastan vișiblemente con la aparente buena marcha del sitio que la crónica regia, pese a las momentáneas dificultadẹs que reconoce, parece reflejar. Conviene recordar que la cancillería regia multiplicó su activiđad durante esta campaña. Se conservan numerosos registros de cartas, tanto procedentes del real cạtalanoaragonés ante Alguer (datadas in obsidione Alguerii) como emitidas en los reinos cismarinos por el infante Pedro, tío y lugarteniente general del rey. Todo ello, además, debe sumarse a la formidable actividad desplegada antes de la partida de la flota, que pone a nuestra disposición cantidades ingentes de información referida a lọs aspectos más variados de esta armada. Esto se debe a que la organización recayó mayoritariamente en la casa del rey y dejó, por ello, evidencias que, en el caso de otras campañas, solían quedar registradas por las comisiones designadas por las cortes y, por ello, no han perdurado. No reviste menor importancia la información recogida en las cartas reales (regestadas en L. D'ARIENZO, Carte reali, pp. 234274) que dan cuenta de numerosas provisiones e informaciones de orden interno, no siempre registradas en los documentos expedidos por el poder regio
} 
El potente dispositivo militar de Pedro de Aragón incluía, obviamente, abundante material de asedio, tanto reutilizado de la campaña del año anterior como traído para la ocasión desde sus reinos metropolitanos ${ }^{85}$. En este aspecto destacaba la presencia de seis "ginys", ingenios de contrapeso para lanzar piedras que, al parecer, debían disponerse en batería para abrir una brecha en las murallas de Alguer por la que los atacantes, aprovechando su superioridad numérica, debían penetrar al asalto. Las piezas de artillería, sin embargo, se hallaban tan mal construidas como dotadas; cuatro de ellas estaban hechas de madera podrida y parte de sus dotaciones, al parecer, eran inexpertas hasta el punto de ser por completo bisoñas ${ }^{86}$.

No fue sólo la artillería la que actuó por debajo de lo esperado, pues también la infantería, reclutada en gran número y con desigual fortuna, resultó ser de escasa calidad. La campaña aquí estudiada contó con un número elevadísimo de peones, mucho mayor de lo habitual, tanto en términos absolutos como en el porcentaje sobre el total de hombres movilizados ${ }^{87}$. El número de 10.000 servents, siempre aproximado, como ya se ha señalado ${ }^{88}$, sólo pudo conseguirse, al menos en el reclutamiento de las compañías regias — distintas de las huestes de los nobles que participaban también en la campañaconteniendo el gasto mediante el pago de salarios bajos a la tropa. Esta medida debió de desincentivar a los profesionales con experiencia (probablemente mejor pagados en otra hueste $u$ otra guerra) y las condestabilías se llenaron de hombres que buscaban los escasos beneficios del servicio armado ${ }^{89}$. Si a esto se suma el hecho de que la tropa debía equiparse por sus propios medios, con un bajo salario y un escaso nivel de exigencia, el resultado fue una infantería en buena medida inexperta, mal cohesionada y precariamente equipada. La situación era particularmente grave en el caso de los ballesteros, entre cuyas filas se notaba más la falta de capacidad técnica y de equipo, ante todo en un asedio, donde las posiciones estáticas potenciaban el combate a distancia y el intercambio de proyectiles ${ }^{90}$.

\footnotetext{
${ }^{85}$ El monarca solicitó el envío del material sobrante a Artal de Pallars, capitán de Cagliari: "Item, volem e·us manam que aquells pichs, càvechs, escales, mantellets e tots los altres arneses de combatre forces que us jaquí lo noble e amat conseller nostre en Bernat de Cabrera, Capità General de Nostres Armades, façats metre en vexell o vexells e trametre on que sapiats que nós hajam presa terra, per què'ns en puxam servir" (ACA, $C$, reg. 1023, fol. 45 r. Playa de Barcelona, 1354, mayo, 5).

${ }^{86} \mathrm{El}$ rey, quejándose a su tío y lugarteniente, le reprendía indignado por haber permitido que algunos buenos profesionales se quedaran en Rosas al partir la armada, que quedaba ahora bloqueada ante los muros de Alguer e incapacitada para derribarlos en poco tiempo (véase R. GUBERN, Epistolari, vol. 1, p. 115).

${ }^{87}$ Expediciones anteriores y posteriores contaban con cantidades menores de combatientes y con menor ratio de infantes, tanto ballesteros como lanceros. Véase por ejemplo el pressupost para la campaña de conquista dirigida por el infante Alfonso en 1323, que llevó consigo 900 hombres a caballo y 4000 de a pie (A. ARRIBAS, La conquista, p. 378).

${ }^{88}$ Véase supra, nota 71.

${ }^{89}$ Descartando como incentivo el bajo salario, quedaba la redención de deudas o crímenes, cuando no el servicio forzado por las autoridades locales o los comisarios de la armada.

${ }^{90}$ El protagonismo de los ballesteros en los combates del sitio de Alguer se refleja en varias cartas de Pedro IV a su tío y lugarteniente, en la que destaca las pérdidas sufridas por éstos (ACA, $C$, reg. 1026, fols. $146 \mathrm{v}$. -asedio de Alguer, 1354, septiembre, 29- y $149 \mathrm{v}$. -asedio de Alguer, 1354, octubre, 23-). La precaria situacion de la infantería generó quejas de los oficiales
} 
Inmovilizado en el asedio de la plaza fuerte, el gran contingente de Pedro el Ceremonioso se encontró con graves problemas logísticos. Ya se ha subrayado la dificultad de las armas catalanoaragonesas para abastecer un contingente de estas características en el contexto que vivía la isla de Cerdeña en 1354. El principal trigal de la zona estaba en manos del juez de Arborea, vivir sobre el terreno era complicado y, además, los territorios regios del sur de la isla habían sido severamente castigados por las fuerzas judicales durante el año anterior. Como ya se ha comentado, el territorio que circundaba Alguer estaba escasamente capacitado para aguantar el ritmo de consumo de recursos de una hueste que no podía abastecerse sólo desde sus bases peninsulares. Los mandos de la armada regia eran hombres técnicamente capacitados ${ }^{91}$, por lo que no debían de ignorar la dificultad de transportar suministros suficientes, ni la amenaza de desabastecimiento que comportaba. El total de los suministros de la armada regia debió de planificarse, probablemente, a partir del consumo de las provisiones que trajo consigo la expedición, de las vituallas procedentes de Sassari y, por último, pero no menos importante, en los stocks almacenados en Alguer ${ }^{92}$.

Los hombres del juez de Arborea y de Matteo Doria, buenos conocedores del territorio en litigio y de las potencias y debilidades de la hueste del rey, demostraron una pericia no menor que la de los mandos enemigos, y adoptaron una estrategia de desgaste, basada en amenazar las posiciones catalanas sin forzar en ningún momento un encuentro frontal. El juez de Arborea estableció su campo en Bosa, mientras se coordinaba con los Doria para lanzar pequeños

regios que se tradujeron en la demanda de refuerzos mejor preparados, obtẹnidos graçias a una política de mejora en los salarios y de aumento de las exigencias de adiestramiento y equipo. Poco después del inicio del sitio de Alguer ya se documenta el cambio descrito (ACA, C, reg. 1606, fol. 24 r. Barcelona, 1354, agosto, 11.). Destaca un documento en el que se ordenó al comisario de la armada, Jaume Desprats, que exigiese un buen nivel de equipamiento, comprobase la aptitud de los ballesteros y les viese tirar con la ballesta antes de reclutarles (ACA, $C$, reg. 1606, fol. 53 v. Barcelona, 1354, agosto, 31. Cit. A. BEAUCHAMP, Gouverner la Couronne, p. 289). La actuación de la infanteria regia en el asalto al Alguer debió de ser mediocre, según la petición de refuerzos en la que, a 26 de agosto de 1354, el rey exige al consejo real de Valencia "CCC ballesters bons e lestiços, que no siguen aytals com aquells qui hic són venguts en aquest viatge, et en haver aquests no hi sia res plaü" (ACA, C, reg. 1026, fol. 119 r. Asedio de Alguer, 1354, agosto, 20-25, datable de forma aproximada por su posición en el registro.) Cabe destacar la existencia de la figura del reconeixedor de armas de los condestables y.peones, que inspeccionaba el armamento de los alistados y les obligaba a comprar equipo si el que aportaban no era suficiente (ACA, $C$, reg. 1400, fol. 110 v., Barcelona, 1354, marzo, 18). Sin embargo, el tiempo necesario para que este cambio fuẹse efectivo ya se había perdido, los avances de los asaltantes eran lentos e insuficientes, y las bajas se multiplicaban. Todo cuanto aquí se refiere a la infantería lo he desarrollado con mayor extensión y profundidad en M. ORSI, "Vaguerosos e malendrins" y "ballesters bons e bé atrecats". Notas sobre la infantería de Pedro el Ceremonioso en una armada real a Cerdeña (1354), en Juan Francisco JiMÉNEZ ALCÁZAR (ed.), Actas del IV Simposio Internacional de Jóvenes Medievalistas de Lorca (2008), en prensa.

${ }^{91} \mathrm{Y}$, no olvidemos, como en el caso del vizconde de Cabrera, incluso veteranos de campañas anteriores en la isla. En 1323 el entonces joven Bernardí de Cabrera, antes de convertirse en el cabeza de casa, privado y vizconde, participó, entre otras campañas, en la expedición de conquista de Cerdeña mandada por el infante Alfonso (PEDRO IV, Crónica, I-35).

${ }^{92}$ Esa era, entre otras, una razón principal para asaltar, frontalmente y de inmediato, la ciudad: la armada regia trató de hacerse con unas vituallas, probablemente acumuladas en gran cantidad para reșistị un largo sitio, que le hubiesen permitido moverse tierra adentro, aprovisionada, hacia tierras judicales. Una vez en territorio arborense el ejército debía mantenerse, en buena medida, a partị de las provisiones saqueadas durante su marcha, aunque apoyándose en la línea de suministro por mar. 
y constantes ataques, centrados en el hinterland de Sassari y en el camino que lo unía con Alguer. Este dispositivo, que por otra parte no tenía nada de extraordinario, era enormemente dañino para las armas catalanas. La cercanía de las tropas judicales — Bosa se halla a pocas jornadas de marcha de Alguery los golpes lanzados por los Doria desde la Gallura desaconsejaban que el ejército del Ceremonioso se dispersara demasiado; éste, por lo tanto, permaneció estático bloqueando Alguer, repartida en varias huestes alrededor de la ciudad, pero con poca capacidad de ir más lejos a correr la tierra enemiga a excepción de algunas cabalgadas, dirigidas desde Sassari por Ramon de Riusec ${ }^{93}$ hacia las tierras de los Doria ${ }^{94}$, que no parece que tuviesen excesivo éxito.

Toda esta casuística llegaba mientras el verano se consumía; las semanas iban pasando y la fortificación de Alguer resistía. Fracasados los intentos iniciales de ataque artillero directo, los sitiadores se aprestaron a presionar con renovado ímpetu ${ }^{95}$. Estos asaltos se cobraron un gravoso tributo humano, destacado por el propio rey en una carta dirigida a su tío en septiembre de 1354, en el que los peones, como es lógico en un cerco y en el asalto a una fortificación, sufrieron la mayoría de las bajas ${ }^{96}$. También la malaria y otras enfermedades, endémicas de cualquier gran concentración de hombres y bestias, sanos, enfermos y heridos, empezaron a asolar el real catalanoaragonés, en una situación que la escasez de víveres tendía a agravar y potenciar ${ }^{97}$. Algo semejante debió de verse entre los animales, ante la falta de pastos y de forrajes, para que el ejército llegara a perder la desastrosa cifra de hasta 400 caballos $^{98}$.

Las continuas incursiones lanzadas contra las posiciones catalanas y contra sus comunicaciones, así como el constante goteo de bajas, obligaron al ejército sitiador a reforzar sus propias defensas, aun a costa de reducir los

\footnotetext{
${ }^{93}$ Cabe destacar aquí que el gobernador Riambau de Corbera, activo servidor de la causa regia, había muerto en agosto de 1354.

${ }^{94}$ Sobre las cabalgadas lanzadas deșde Sassari, véase J. ZURITA, Anales, VIII-55. Se menciona no sólo la cabalgada sino también el intento del rey de controlar el reparto de los escasos bienes obtenidos (ACA, C, reg. 1026 , fols. 100 v. -asedio de Alguer, 1354 , julio, 13-y 152 v. -asedio de Alguer, 1354, noviembre, 3-). Estas cabalgadas permitieron la circulación de buenos stocks de ganado y productos de consumo básico, pero todo ello resultaba insuficiente y costaba numerosas bajas a los incursores (ACA,C, reg. 1026, fol 152 v. Asedio de Alguer, 1354, noviembre, 3.). El alcance y el impacto de una incursión de saqueo era directamente proporcional al número de tropas participantes, y el ejército del rey de Aragón no podía destinar demasiadas a forrajear lejos del real; sobre el funcionamiento de las cabalgadas y los hombres destinados a ellas desde los campamentos del ejércit, véase N. CoVINI, Studiando, p. 239.

${ }^{95}$ Los zapadores de Pedro IV destinaron ingentes esfuerzos a rellenar el foso y llevar hasta el muro una torre de asalto, cubierta de pieles sin curtir, mientras seguían tratando de debilitar o derribar el muro con arietes y labor de zapa. Así lo refiere el rey Pedro a los jurados de Valencia, en una carta del 23 de julio de 1354 (ACA, C, reg. 1026, fol. 103 r. Asedio de Alguer, 1354, julio, 23).

${ }^{96}$ El desigual reparto de las bajas era moneda común, pero en caso de un sitio los peones solían llevar aún más el peso de la lucha. La mención a las numerosas bajas aparece en ACA, $C$, reg. 1026, fol. 106 r. Asedio de Alguer, 1354, julio, 30).

${ }^{97}$ Es obvia la relación directamente proporcional entre escasez alimentaria y vulnerabilidad ante la enfermedad, constatada con frecuencia en fuentes y estudios (J. GILLINGHAM, "Richard I", p. 308).

${ }^{98} \mathrm{ACA}, C$, reg. 1026, fol. 146 v. Asedio de Alguer, 1354, octubre, 4. Conviene subrayar esta cifra como terribiemente grave, pues un ejército como el del Ceremonioso sin una caballería apropiada quedaba en graves dificultades, falto de medios de reconocimiento y de tropas de choque.
} 
recursos destinados a atacar Alguer y a forrajear; era prioritario compensar las pérdidas derivadas de los combates y de las enfermedades, poder enviar refuerzos a Sassari y asegurar las comunicaciones con Alguer ${ }^{99}$. Al mismo tiempo, Pedro IV, para prevenir salidas de la guarnición, la llegada de un ataque o la entrada de socorros desde el exterior, hizo fortificar el real que bloqueaba Alguer $^{100}$. No parece que el rey ni sus consejeros hubiesen previsto esta eventualidad; como ya se ha dicho, todo apunta a que la campaña se planificó como una serie de maniobras dinámicas, y no como un sitio en el que los atacantes necesitasen defensas estáticas ${ }^{101}$.

En octubre de 1354, cuando las fuerzas catalanoaragonesas estaban ya considerablemente debilitadas por el desgaste del sitio, Mariano de Arborea se presentó, al mando de un numeroso ejército (2000 hombres a caballo y 15.000 de a pie), cerca de las posiciones del Ceremonioso ${ }^{102}$. Este debió de ser un momento crítico para las tropas regias que, sin duda, ante la amenaza de un ataque directo que podía golpearlas cuando estaban dispersas, debieron replegarse y concentrar sus fuerzas en las proximidades de Alguer. Este hecho aumentaba la gravedad de los problemas expuestos más arriba: las condiciones de hacinamiento e insalubridad, la incapacidad de desplegarse por el camino de Sassari para asegurar el abastecimiento y las comunicaciones, la escasez de vituallas y lo avanzado del otoño ofrecían pocas oportunidades al ejército real si la situación no cambiaba; Mariano IV no tenía siquiera que atacar, pues le bastaba con mantener el equilibrio de la situación y esperar el agotamiento enemigo.

Además, conviene no olvidar que además se rumoreaba que el común de Génova tenía presta una nueva flota y se disponía a lanzarla contra la escuadra catalana que bloqueaba Alguer. El rey conocía los posibles planes para

\footnotetext{
${ }^{99}$ Los botines de las cabalgadas, junto a otras provisiones procedentes de Sassari, debían llegar al reạl alguerés a través de un camino peligroso, llano, sin puntos de fácil defensa y vulnerable a las incursiones desde el norte o el sur. Aun sin conocer la configuración exacta del paisaje y del territorio alrededor de dicho camino en el siglo XIV, creo que no es desacertado considerarlo, en el contexto de la campaña de 1354, como peligroso para quien llevase provisiones por él. Su orografía llana dificultaba, probablemente, el establecimiento de puntos de observación, y permitía que cualquier transporte de material -con recuas o carros- fuese vulnerable a una incursión de enemigos montados. El rey estableció un complejo sistema de vigilancia a lo largo de sus posiciones, prestando especial atención al camino que unía Cagliari y Alguer, en el que se establecieron guardas y escuchas y un estricto régimen de control de la circulación de personas y bienes, obligados a viajar en grupos numerosos y provistos de autorización. Véase infra, nota 123.

${ }^{100}$ A. GIMÉNEZ SOLER, El viaje, p. 92; ACA, C, CR, Pedro III, caja 43, c. 5329. Asedio de Alguer, 1354, julio, 1. Regestada en L. D'ARIENZO, Carte reali, doc. 488. Hay que destacar el hecho de que ésta era una táctica defensiva habitual, como puede verse, por ejemplo, en Josep CASAS I GENOVER; Josep Maria LLORENS RAMS, Un camp militar medieval a Viladamat (Alt Empordà), "Annals de l'Institut d'Estudis Gironins" 33 (1994), pp. 517-526.

${ }^{101}$ Así parece confirmarlo el hecho de que, ante la necesidad urgente de madera para hacer empalizadas, los oficiales regios compraran varias embarcaciones y las desmantelaran. Sirve de ejemplo la orden de pago de 150 reales de Mallorca que se debían a Bernat Galí, por una nave desguazada para obtener madera (ACA, C, reg. 1026, fol. 157 v. Asedio de Alguer, 1354, noviembre, 2).

${ }^{102}$ Pese a que durante el verano quedó a la espera, como se ha dicho, en Bosa, cuando la hueste de Pedro el Ceremonioso estuvo suficientemente desgastada, Mariano IV empezó a reclutar sardos para contraatacar o forzar una negociación, según refería al monarca en una carta el capitán de guerra de Cagliari, Artal de Pallars (ACA, C, CR, Pedro III, caja 43, c. 5364. Cagliari, 1354, octubre, 14. Regestada en L. D'ARIENZO, Carte reali, doc. 508).
} 
un ataque combinado por tierra y mar, por parte del juez y de la flota genovesa; en caso de vencer en cualquiera de ambos elementos, los rebeldes y enemigos del Ceremonioso podían acorralar y llevar a la rendición incondicional, cuando no al cautiverio o a la aniquilación, a toda la armada. En caso de batalla campal, el juez de Arborea disfrutaba de una ventaja considerable, pues contaba con tropas frescas y aprovisionadas, mientras que la hueste del rey de Aragón, tras meses de sitio, epidemias, combates y escasez, estaba fuertemente mermada tanto en personal como en caballos, y ya no era la temible fuerza del verano anterior. Por su parte, los catalanes ya no tenían tiempo ni capacidad de explotar una hipotética victoria en batalla campal, mientras que una derrota, en territorio enemigo y sin opciones de retirada segura, no sólo era probable sino que podría haber sido desastrosa.

Pedro el Ceremonioso aceptó negociar. En noviembre de 1354, tras un largo sitio, Alguer abría las puertas al, rey, después de que éste, enfermo pero aún obstinado, acabase aceptando, a petición de Bernat de Cabrera, que este noble y Pedro de Ejérica (cuñado del juez) saliesen del real y negociasen una tregua. Pese a las protestas del rey, éstos se vieron forzados a aceptar unas condiciones que representaban un claro fracaso ante las pretensiones iniciales de la expedición ${ }^{103}$. La resistencia de un punto fortificado, combinada con la amenaza impuesta a una distancia prudencial y con rápidos contraataques a las líneas de abastecimiento, daba, como era habitual, sus frutos ${ }^{104}$. Como solía ocurrir en la guerra medieval, el ya citado reflejo obsidional otorgaba la ventaja y el éxito a quienes adoptaban estrategias defensivas en puntos fortificados ante un ejército atacante.

\section{LA LOGÍSTICA}

Obviamente, la armada real, numerosa y combatiendo en un territorio empobrecido y hostil, necesitaba una potente organización logística. Dar un perfil exacto de esta organización es inviable, ya que no necesariamente responde a un funcionamiento claro y estandarizado, pero sí puede decirse que, basándose tanto en una lógica de centros y periferias como en una cierta especialización regional y social, seguía unos rasgos básicos que se intentarán esbozar. Puesto que la logística y el avituallamiento son una parte básica de cualquier guerra ${ }^{105}$, resulta aún más determinante en el caso de las armadas y

${ }^{103}$ G. MELONI, Genova e Aragona, vol. 1, p. 214.

${ }^{104} \mathrm{El}$ dispositivo de las fuerzas judicales y de los Doria es casi paradigmático, muy similar a lo que se establece como cánon de estrategia defensiva en J. GILLINGHAM, "Richard I", pp. 307308 .

${ }^{105}$ Hay estudios que han subrayado la importancia del avituallamiento de los ejércitos de la Corona de Aragón, véase M. SÁNCHEZ, Guerra, avituallamiento del ejército y carestias en la Corona de Aragón: La provisión de cereal para la expedición granadina de Alfonso el Benigno, "Historia, instituciones, documentos" 20 (1993) pp. 523-549; Carles VELA AULESA, Per co com gran fretura és de vianda en la nostra host. L'avituallament de l'exèrcit de. Jaume II en la campanya de Múrcia (1296), "Anales de la Universidad de Alicante. Historia Medieval" 11 (1996-1997), pp. 599-630. 'Destaca, para la armada real de 1354, A. BEAUCHAMP. Que ivarcosament nos trametats. Mucho mayor atención ha recibido la logística en la historiografía anglosajona; véase por ejemplo M. PRESTWICH, Victualling Estimates for English Garrisons in 
expediciones dirigidas a Cerdeña, territorio insular, situado lejos de las bases peninsulares de las fuerzas reales y con escasa capacidad para soportar ejércitos numerosos sobre el terreno. Conviene destacar aquí, sin embargo, que, si bien las fuerzas regias disponían al inicio de la campaña de una línea de abastecimiento por mar, ésta no dependía enteramente de los barcos fletados por la armada. Estaba, además, pensada — tal vez por lo imposible de plantearse otra cosa - para abastecer el real durante poco tiempo, apoyando después a un ejército en movimiento capaz de forrajear eficazmente $\mathrm{y}$, por lo tanto, menos necesitado de víveres. Todo ello llevó a la estructura logística de la armada al límite de sus capacidades y ésta, escasa de medios, se fue debilitando, con lo que tuvo que dar paso a la creciente participación de particulares; éstos contribuyeron a abastecer el real pero, obviamente, buscaron y encontraron un beneficio rápido en el elevado precio de unas mercancías escasas.

\section{La alimentación del ejército}

La alimentación del ejército fue, obviamente, una prioridad básica para el rey y todos los encargados de los negotia armate. Si bien frecuentemente se ha prestado atención a la organización del dispositivo de recaudación y distribución de los alimentos, resulta mucho más difícil acercarse realmente al significado de las vituallas en la vida diaria de una armada, y al modo en que la procedencia y situación de los alimentos marcaba el devenir de la guerra. El análisis de los documentos puede llevar a desglosar la composición de los conjuntos de productos, llamados genéricamente vitualles, así como a detectar la mutación de su valor, tanto económico como estratégico, a causa de la coyuntura de guerra. Su clasificación, por todo ello, no tiene por qué ser sólo tipológica, sino que también puede responder a la titularidad de su adquisición $\mathrm{y}$ al acceso que tenían a ellos los diferentes miembros de la $\operatorname{armada}^{106}$.

Scotland during the Early Fourteenth Century, "The English Historical Review" 82-324 (Julio1967), pp. 536-543; IDEM, Armies and Warfare, pp. 245-262. Entre otras aportaciones, cabe destacar las de J. GILlINGHAM, Richard I; asi como B. S. BACHRACH, Crusader Logistics: from victory at Nicaea to resupply at Dorylaion, en J. PRYOR (ed.), Logistics of Warfare in the Age of the Crusades. Proceedings of a workshop held at the Centre for Medieval Studies, University of Sydney, 30 September to 4 October 2002, Hampshire, Ashgate, 2006, pp. 43-62; Mark Kennedy VAUGHN, "Mount the War Horses, Take your Lance in your Grip..." Logostics Preparations for the Gascon Campaign of 1294, en M. PRESTWICH; Richard BRITNELL; Robin FRAME, Thirteenth Century England VIII. Proceedings of the Durham Conference 1999, Woodbridge, Boydell Press, 2001, pp. 97-112.

${ }^{106}$ La documentación ofrece, una vez más, datos más precisos sobre los hombres enrolados en la flota -donde se da una mayor presencia del componente público en la gestión- que sobre el resto de combatientes. Si bien en principio todo combatiente de la armada debia alimentarse comprando comida con su salario, se sabe que la armada proporcionaba bizcocho a los marineros enrolados en sus galeras, a través de los cómitres de éstas; probablemente era la estrecha convivencia y, la delicada logística de los barcos lo que llevaba a que en ellos hubiese una mayor reglamentación. No se puede saber con exactitud la distribución exacta del producto, entre otros motivos porque se prevé la posibilidad de que un marinero, como cualquier otro combatiente, se procure la alimentación con su salario. Sin embargo, las ordenanzas navales emitidas en 1359 no preven otra cosa que cantidades de bizcocho y pan (Antonio de CAPMANY Y MONPALAU, Ordenanzas de las armadas navales de la Corona de Aragón, aprobadas por el rey D. Pedro IV, año de MCCCLIV, Madrid, Imprenta Real, 1787, p. 101). Por ello, parece claro que incluso en la flota los companajes debían correr a cargo del propio combatiente, y en función, claro está, de su salario. Un remero, con un salario cercano a un sueldo diario, debía complementar, con companajes pagados de su paga, el aporte de energia del pan, hecho desproporcionado con el trabajo que 
En primer lugar, es de sobras aceptado que el pilar principal de la alimentación de la población en el occidente bajomedieval era el pan de cereales, entre los cuales el trigo era sin duda el más valorado. Sin embargo, se conoce también que las circunstancias de los viajes y de las guerras, traducidas en transporte y almacenaje, impedían que el pan y otros productos frescos se conservasen adecuadamente, por lo que el ejército real que asedió Alguer se abasteció mayoritariamente, como era habitual en campaña, de bizcocho. Las referencias a la alimentación exacta y a las raciones diarias para tropas en campaña - no necesariamente iguales a otras cantidades, más estables, asignadas a guarniciones de plazas fuertes-, son difíciles de hallar ${ }^{107}$. Sin embargo sí se encuentra, desde los primeros momentos de la organización de la campaña, una constante labor de oficiales regios y comisarios de la armada en la compra de bizcocho o en la adquisición de stocks de trigo y en su panificación $^{108}$.

El bizcocho, sin embargo, debía acompañarse con otras aportaciones calóricas y energéticas para mantener un combatiente operativo. Por ello, los oficiales regios y comisarios de la armada se ocupaban también de gestionar envíos de varios productos desde los reinos metropolitanos ${ }^{109}$ y desde Sassari ${ }^{110}$. Estas vituallas - principalmente carnes, imprescindibles por sus aportaciones de proteínas y grasas y por su relativa facilidad de conservación - servirían como companajes o tendrían más peso en la dieta, en función del poder adquisitivo de los compradores ${ }^{111}$. Sabemos que los artículos que acompañaban

debía realizar. Sobre los problemas alimentarios de la chusma de las galeras véase P. SIMBULA, Note sull'alimentazione a bordo delle navi del Basso Medioevo, "Medioevo. Saggi e rassegne" 15 (1990), pp. 21-42; M. ORSI, Les dotacions, p. 64-65. Resulta muy útil, referida a los tipos de dieta de las tropas en función de las circunstancias, la aportación de P. CONTAMINE, Guerre, état et société, pp. 646-654.

${ }^{107}$ Las guarniciones, normalmente estables, comunicadas con el traspaís que controlaban o abastecidas por él, solian tener raciones estandarizadas, mientras que las flotas o tropas en campaña, por su situación de movilidad constante en territorio hostil, sufrían sin duda una coyuntura mucho más variable que repercutía en la estabilidad, cantidad y calidad de sus alimentos; véase P. CONTAMINE, Guerre, état et société, pp. 646.

${ }^{108} \mathrm{El}$ mecanismo de captación y distribución del trigo y el bizcocho merecería un estudio pormenorizado para esta campaña, enormemente rica en documentación. Destaca, como eje de circulación del trigo, la cuenca del Ebro: por ejemplo, el 2 de marzo de 1354 se ordenó al justicia de Aragón y al merino de Zaragoza que comprasen trigo en Aragón y lo enviasen a Tortosa donde otros oficiales -Nicolau Burgues y Martín Pérez Pelegrí- lo recogerían para panificarlo allí (ACA, C , reg. 1147, fol. $27 \mathrm{r}$. Alcañiz 1354, marzo, 11.). Parte de ese stock lo recogió finalmente Bernat Mascurt, escribano del Maestre Racional, para llevarlo a Barcelona, donde se gestionaría su envío a Cerdeña (ACA, RP, MR, vol. 642, fol. 137 v. Barcelona, 1356, enero, 30.).

${ }^{109}$ Los comisarios de la armada, siguiendo las instrucciones de los consejos reales y del lugarteniente general, compraban tambien nutridos stocks de vituallas, que otros comisionados solían gestionarr para su reunión y envío a Cerdeña. Por ejemplo, Bernat Saera rindió cuenta de su gestión en la compra, por orden del infante Pedro, de capones, gallinas, trigo, huevos, avena, mijo y legumbres (ACA, $R P, M R$, vol. 642, fol. 269 r. Barcelona, 1356, octubre, 26).

${ }^{110}$ Véase infra, nota 111.

${ }^{111}$ Resulta muy útil, como ejemplo de la necesidad de companajes y complementos de un ejército en campaña, el desglose de vituallas en una carta de Pedro IV a su tío, el lugarteniente general Pedro, conde de Ribagorza:

"Car de part del mon vianda aci a nos ne a la host no ha venguda sino aquella qui vench ab nosensemps ne de la isla ne podem gens haver per tal car sol I sart no ses a nos convertit encara ans son axi obstinats en lur rebellio com dabans axi que nelex carn fresca de neguna lyg no sic troba a ops de la ost e siu fa es tan poca e tan cara que I bou sic ven X lliures, I moltó XL sous, 
el bizcocho no se incluían ni siquiera en la panàtica debida por la flota a sus hombres, por lo que cabe deducir que cada hombre los pagaba, si podía, de su salario. Este hecho generaba automáticamente una especulación alrededor de los productos descritos, y la escasez provocada por la presencia del ejército junto a Alguer dio lugar a un constante fenómeno de alza de precios de las vituallas que, pese a los intentos del rey de prohibirlo ${ }^{112}$, debió de empeorar enormemente la situación de buena parte de la tropa y dejarla vulnerable ante la insalubridad y las epidemias que se extendían por el real catalán.

Debe subrayarse aquí la importancia de un recurso imprescindible que no siempre recibe la atención que merecería en los estudios de historia militar: el agua ${ }^{13}$. Sitiar una población implicaba hallarse cerca de sus fuentes de aprovisionamiento hidráulico. Sin embargo, lo lógico era que cualquier ejército mínimamente numeroso - provisto, obviamente, de gran cantidad de caballos y bestias de carga - tuviese problemas para acceder cómodamente al agua, en cantidad razonable y con garantías de salubridad, en un entorno que se contaminaba apenas el ejército se detenía unos días en él. Las consecuencias de las aglomeraciones se podían atenuar separando entre sí las distintas huestes o contingentes, pero esta solución era sólo parcial: una dispersión excesiva dificultaba, como se ha dicho, la coordinación de esfuerzos y exponía las distintas fuerzas sitiadoras a sufrir un contraataque enemigo sin poder prestarse apoyo. Está claro, además, que la capacidad de fortificar y proteger el real catalán — precaución, como se ha comentado, necesaria para asegurar el acceso y el apoyo a Sassari - era, obviamente, inversamente proporcional al perímetro de éste ${ }^{114}$.

Por todo ello, si bien los caminos y el relieve del terreno condicionaron el movimiento de los ejércitos, conviene plantearse el acceso al agua como uno más - y no el menor - de los muchos problemas que debía sopesar un mando para tomar decisiones operacionales y tácticas

e I parell de gallines XXV e XXX sous, I parell de perdius I florí e I escut dor e axi vos altres vejats en quin punt som car siats certs que si cuytadament e poderosa accorreguts no som de les dites coses, vergonyosament e confusa haurem a desemparar, ço que Deus no vulla, aquest fet e per consegüent perdre la isla" (publicado en A. GIMÉNEZ SOLER, El viaje, p. 93).

Pedro IV trató de impedir que se comprasen carnes en Sassari y se revendiesen más caras a los sitiadores, tal como especifica en las ordenes dadas a Ramon de Riusec, capitán de la plaza de Sassari; G. Meloni, Genova e Aragona, vol. 1, p. 200.

${ }^{113}$ Cabe destacar la excepción de los estudios sobre las cruzadas, donde la necesidad de agua además de ser mayor que en otros climas, se cebaba en los francos, poco acostumbrados a aquel entorno, por lo que con frecuencia aparecía en las fuentes; véase R. C. SMAIL, Crusading warfare, pp. 138-203. También cabe destacar aportaciones válidas para el tratamiento del agua en L. CIFUENTES, La medecina medieval en els viatges per mar, "Mot, so, razo" 3 (2004), pp. 35-44.

${ }^{114}$ Las defensas y estructuras que rodeaban el real se mencionan de forma secundaria en algunas cartas; se trataba de castells de fust, terraplenes y empalizadas que defendían o unían las distintas huestes acampadas alrededor de Alguer, conformando, probablemente, una obra de fortificación considerable (ACA, C, reg. 1026, fol. 149 r. Asedio de Alguer, 1354, noviembre, 23.). 
Vinculada parcialmente al consumo de agua, la presencia de vino ${ }^{115}$ en los envíos de vituallas desde los reinos metropolitanos por el lugarteniente y los consejos fue también constante. El vino, además de servir para beber solo, contribuía a potabilizar el agua y servía como complemento alimentario que ayudaba parcialmente a paliar los déficits de la dieta diaria de un combatiente. La sanidad de la época recomendaba su consumo habitual, y con mayor vehemencia en caso de viaje. Por ello, las autoridades competentes velaron siempre, en la medida de lo posible, por el suministro regular de vino a sus ejércitos de maniobra y a sus guarniciones encastilladas, permitiendo, conviene subrayarlo, su venta y consumo entre la tropa bajo cierta reglamentación que evitase abusos tanto en su consumo como en su precio ${ }^{116}$.

Como último producto de primera necesidad para la armada se debía incluir, dentro de las vituallas, el centeno para los caballos. Las bestias, y sobre todo aquellas destinadas al combate, eran particularmente caras y, si bien en climas más húmedos podían alimentarse de pasto, esto se volvía difícil en el verano mediterráneo, e incluso dramático en caso de un sitio prolongado, en el que los sitiadores rápidamente consumían las hierbas aptas de las cercanías.

Pese a todo, sólo se ha hablado, hasta ahora, del trabajo de los entes públicos para procurar suministros básicos a la armada. Los hombres que pasaron a Cerdeña con Pedro el Ceremonioso consumían una cantidad de vituallas básicas que, aun siendo parte prioritaria de las cargas transportadas por los barcos de la armada, no podía proporcionarse por completo a través de ellos $^{117}$. La armada se planificó para proporcionar suministros que sus hombres pudiesen comprar ${ }^{118}$, previendo que la oferta y la abundancia de stocks crecerían con la toma de Alguer y el saqueo del territorio arborense; lo cierto es que, con el ejército estático, los aportes de la armada resultaban insuficientes, y se abrió la puerta a la iniciativa privada. En ese momento, ante la perspectiva de ganancias rápidas y de poder navegar libremente tras hacer escala en el real de

\footnotetext{
${ }^{115}$ Abundan los ejemplos de envíos y peticiones de vino y de vinagre; sirva de ejemplo la petición regia de estas y otras vituallas en ACA, C, reg. 1026, fol. 149 v. Asedio de Alguer. 1354, octubre, 10 .

${ }^{116}$ Las ordenanzas de 1354 , por ejemplo, contemplan la posibilidad de que naucleros i proeles vendiesen vino; A. de CAPMANY, Ordenanzas, p. 87.

${ }^{117}$ Recordémoslo, un ejército de maniobra de 15.000 hombres y 3.000 caballos y una flota que, tal vez, rondaba los 11.000 tripulantes. En este cómputo no se contabilizan las bestias de carga ni otros acompañantes propios de toda expedición, como los séquitos personales de nobles y caballeros, las prostitutas ó los mercaderes. El ejército sitiador podría llegar a consumir al día hasta 60.134 kifogramos sólo en los productos de subsistencia; la cifra se basa en el cómputo de 1.159 gramos de trigo por persona y día y 10 kilogramos de centeno por caballo y día; véase $M$. SÁNCHEZ, Guerra, avituallamiento, pp. 527-528. No muy distinto en cuanto al grano, pero incluyendo el companaje, sería el cálculo de Yuval N. Harari, que establece el consumo en 1.250 gramos de pan y 1.330 gramos de carne por hombre y día, dando también 10 kilogramos de cebada a cada caballo. Este cómputo daría la cifra de consumo de 97.080 kilogramos diarios para el ejército; véase Yuval N. HARARI, Strategy, pp. 304-305.

${ }^{118}$ Los campamentos de los ejércitos debían tener victualia copiosum mercatum para que los hombres se abasteciesen; véase J. GILLINGHAM, Richard I, pp. 308-309. Se documenta, en efecto, la existencia de un mercado, donde los mercaderes tienen botiga propia, en el real de Alguer (ACA, C, reg. 1026, fol. 149 r. Asedio de Alguer, 1354, octubre, 3.).
} 
Alguer, numerosos particulares acudieron a vender vituallas a su mercado ${ }^{119}$. Este canal de abastecimiento, si bien ofrecía a la armada mayores opciones de suministros, traía consigo, al estar movido por la opción de lucro mediante la venta de bienes escasos, un obvio aumento de precios en productos de primera necesidad para las gentes de armas.

\section{El transporte}

Ya se han dado algunos apuntes sobre las distintas acciones llevadas a cabo por los diferentes poderes, instituciones y particulares para satisfacer las necesidades logísticas de ejércitos y flotas. Estas iniciativas se entrelazaban formando un denso tejido socioeconómico de redes clientelares, intereses mercantiles, necesidades militares y obligaciones políticas que no siempre apuntaban en la misma dirección. Esta problemática influía notablemente en las diversas formas en que se materializaba el esfuerzo de transportar el material que se destinaba a barcos y tropas que combatían en Cerdeña.

Es bien sabido que el barco era, en el siglo XIV, el sistema más eficiente y económico de transportar gran cantidad de material a grandes distancias, optimizando el coste de medios y mano de obra. La armada regia a Cerdeña fue una punta ascendente extraordinaria en los esfuerzos militares de la Corona de Aragón y, al unir esfuerzos de todos los reinos, sus responsables debían organizarla y coordinar los barcos que tenían que transportar y avituallar la armada. Las rutas de transporte de material y movimiento de gentes de guerra por tierra confluían hacia los puertos de embarque por los caminos habituales, aprovechando la red de comunicaciones: los ejes eran, obviamente, los caminos reales — principalmente la antigua Via Augusta - y, para personas y bienes rurales procedentes de Aragón, el Ebro ${ }^{120}$. Los puntos de reunión eran, por lo tanto, los puertos principales: Valencia, Tortosa, Barcelona y Collioure. Se deben sumar además, aunque en menor medida, Tarragona, Sant Feliu de

\footnotetext{
${ }^{119}$ Pese a tener este particular una gran importancia, lo cierto es que apenas se refleja, salvo por referencias secundarias, en la documentación pública. Se sabe, sin embargo, que la posesión y mercadeo de vituallas, negocio rentable en contextos de guerra alrededor de los ejércitos en campaña, lo fue cada vez más a medida que avanzaba la campaña y el real se desabastecía. Así lo atestigua el hecho de que, ante la escasez de naves de la armada, el rey, tras meses de intentar controlar y reclutar cualquier barco disponible, diese licencia para viajar a cualquier destino, a condición de pasar obligatoriamente por Alguer a abastecer el ejército. Esta medida sentó precedente, y pronto, el 22 de agosto de 1354, se usó la licencia de navegar como moneda de cambio para atraer productos al mercado de los sitiadores (ACA, $C$, reg. 1026, fol. 122 r. Asedio de Alguer, 1354, agosto, 22). El rey concedió incluso licencia de vender en el real al precio de eleccion del mercader, garantizando la no confiscación del stock, a varios patrones de leno. (ACA. $C$, reg. 1026, fol. 117 r. Asedio de Alguer, 1354, agosto, 25.). El paso de la confiscación y la movilización forzosa al incentivo economico da idea de la insuficiencia del mecanismo público parạ procurar alimentos al ejército. La opción de lucro daba lugar a la posibilidad de crear sociedades mercantiles, cuya rentabilidad atraía, junto al capital mercantil, la participación de otro tipo de profesionales; es el caso del notario Bernat Mascurt, que invirtió 50 libras en una sociedad creada para navegar, mercadear y vender vituallas a la armada regia (AHPB, Jaume Ferrer, Llibre Comú, 19/18, fol. 91 r. Barcelona. 1354, abril, 28).

${ }^{120}$ Véase A. RIERA, El sistema viario de la corona catalanoaragonesa en la Baja Edad Media en S. GENSINI (ed.), Viaggiare nel medioevo, pp. 421-446, así como también A. SESMA, Centro de producción y redes de distribución en los espacios interiores de la Corona de Aragón: materias primas y productos básicos, en R. NARBONA (ed.), La Mediterrània de la Corona d'Aragó. XVIII Congrés d'Historia de la Corona d'Arago, pp. 903-938. Ya se ha comentado la crucial importancia de los stocks de grano aragones canalizados por el Ebro, véase supra, nota 108.
} 
Guíxols y Mallorca ${ }^{121}$. Este último puerto, sobre todo en la fase inicial de los preparativos de la expedición, dejó en segundo lugar su papel de punto de reunión de material y personas para convertirse en punto de encuentro y base de los barcos de transporte. También en Cerdeña, obviamente, trabajaron los fieles a Pedro de Aragón para acumular suministros en Cagliari y Sassari.

En la expedición estudiada aquí es necesario distinguir el embarque masivo, realizado en el momento inicial de cada campaña, de los posteriores envíos de refuerzos, noticias y material. Procedente de los distintos puntos de reunión - Valencia para gentes y materiales de dicho reino, Barcelona para catalanes y aragoneses, Collioure para los procedentes del Rosellón - la flota se recogió en Rosas a mitad de mayo. Desde allí zarpó, en un primer viaje, casi todo el contingente, que desembarcó en Porto Conte ${ }^{122}$. Posteriormente, desde cada uno de los puertos implicados en la logística, fluyó el tráfico marítimo hacia el real de Alguer, siempre con la premisa de unir cargas de diferentes puertos para poder reducir el número de viajes y garantizar su seguridad navegando en conserva. También, una vez formalizado el sitio de Alguer, se activó una ruta constante de avituallamiento desde Sassari y, en menor medida, desde Cagliari ${ }^{123}$.

Es difícil establecer un perfil general y estable de los barcos usados para el transporte en las expediciones militares en pleno siglo XIV y las armadas movilizadas por los reyes de Aragón contra sus enemigos en Cerdeña no son una excepción. Sabemos que la armada fletó varios barcos, situados directamente bajo las órdenes de los mandos y comisarios de la armada. Estos solían ser, a excepción de los ujieres, de titularidad privada, según se deduce de sus patronías $^{124}$, y se ponían al servicio de la expedición a un precio determinado

\footnotetext{
${ }^{121}$ Así se deduce de las menciones que aparecen en los documentos regios, entre los que cabe destacar una carta enviada por el rey a su tío y lugarteniente, el infante Pedro, en la que menciona el envío de varias naves desde el real para cargar suministros en los reinos cismarinos y en Mallorca; tres de ellas se dirigirían a Valencia, dos a Tortosa, una a Tarragona, una a Mallorca, una a Sant Feliu de Guíxols y otra a Collioure (ACA, C, reg. 1026, fol. 139 r. Assedio de Alguer, 1354, septiembre, 25.). Si bien en el citado documento no se nombra Barcelona, parece innecesario recordar aquí su papel centrạl como punto de transporte, industria y mercado. Sirva de ejemplo el hecho de que fuese escogida como sede de uno de los consejos reales y punto de reunión, de pago y de embarque para los caballeros convocados en Cataluña (AHCB, Consell de Cent, Ordinacions originals XV1-2, fol. $1 \mathrm{r}$. Barcelona, 1354, enero, 17.).

${ }^{122}$ PEDro IV, Crónica, V-36.

${ }^{123}$ Destaca la ruta que unía Sassari con Alguer, por la que llegaba el suministro procedente de las cabalgadas contra tierra de los Doria y el material que se descargaba en Porto Torres; así parece indicarlo la carta que mandó Ramon de Riusec, capitán de Sassari, informando al rey de la puesta en marcha de numerosos carros para llevar vituallas de Porto Torres a Alguer (ACA, $C$, $C R$, Pedro III, caja 43, c. 5348. Sassari, 1354, noviembre, 5.). Sin embargo esta ruta, como se ha comentado, era también difícil de mantener operativa, a causa de la presión de los rebeldes sobre ella. Se registra también, el 19 de agosto de 1354, la orden emitida a Artal de Pallars, capitán de Cagliari, de favorecer la misión de Joan Palomar, portero real, que viajaba a Cagliari con 2 ujieres para cargar pan (ACA, C, reg. 1026, fol. 113' v. Asedio de Alguer, 1354, agosto, 19.).

${ }^{124}$ Importa recordar que la asimilación entre patrón y embarcación implica que los barcos cambiaban de nombre con cierta frecuencia. Es, por ello, difícil dar un número exacto de embarcaciones adscritas a la armada. Véase Núria COLL I JULIÂ, Aportación al estudio de los patrones y de la propiedad de las naves en Cataluña en la Baja Edad Media, en Jordi MALUQUER DE MOTES (ed.), Homenaje a Jaime Vicens Vives, Barcelona, Universidad de Barcelona-Facultad de Filosofía y Letras, 1965, vol. 1, pp. 377-393. Los ujieres, en cambio, constituían una tipología a medio camino entre las galeras y los barcos redondos, y en las armadas solían ser de titularidad pública, armados y clasificados, junto a las galeras, como barcos de guerra; véase infra, nota 133.
} 
por unidad de carga — procedimiento conocido como flete a escar-, durante un tiempo que solía ser de cuatro meses ${ }^{125}$. Si los documentos regios daban una cifra prevista de 20 naves en la armada, podría decirse que se acercó considerablemente al número de barcos que, al parecer, se fletaron al servicio de la armada entre mediados y fines de abril de $1354^{126}$.

Pese a los recursos humanos y materiales movilizados por los comisarios regios, las necesidades del transporte obligaron a movilizar forzosamente todas les embarcaciones disponibles. La base de esta movilización fue la isla de Mallorca, cuyo gobernador, Gilabert de Centelles, fue encargado de detener todas les embarcaciones disponibles y aptas, prohibir que abandonasen la isla y asignarles, en función de su tipología, el tipo de carga más apropiado antes de enviarlas a reunirse en Rosas ${ }^{127}$. Una vez terminada la travesía inicial, el infante Pedro, lugarteniente general, y los consejos reales se encargaron del transporte de vituallas mediante los barcos fletados, que hicieron numerosos viajes.

Los barcos documentados para las funciones de transporte se pueden clasificar en tres grandes grupos. En primer lugar se registra la presencia de naves o cocas, que podían recibir varias denominaciones ${ }^{128}$. Se utilizaban para

\footnotetext{
${ }^{125}$ Un mecanismo no demasiado distinto al de cualquier iniciativa comercial, salvo por el hecho de que la guerra obligaba, a petición de la corte y como parte intrínseca del contrato, a embarcar un mayor número de combatientes; Joan Lombarda tenía en su nave tota la companyia que tenirhi deviets segons la forma del noliejament quin fo fet (ACA, RP, MR, vol. 642, fol. $45 \mathrm{v}$. Barcelona, 1354, diciembre, 20). La participación de los oficiales reales como fletadores es constante; por ejemplo, en una carta del infante Pedro se menciona a Bernat Joncar y a Bernat Bonet, patrones de coca, que habían obtenido dinero del consejo de Barcelona, por 4 meses de flete, para llevar vituallas y ballesteros $(A C A, C$, reg. 1606 , fol. 102 r. Barcelona, 1354, octubre, 18). También, por supuesto, los oficiales de la armada aprovechaban viajes de particulares que pasasen por Cerdeña, entregándoles materiales de la armada que ocupaban una parte de la carga; véase la ordren de Pedro IV a Garcia de Loris de enviar ciertas vituallas en naves que navegasen hacia Cerdeña (ACA, C, reg. 1400, fol. 26 r. Barcelona, 1354, enero -datable alrededor del 20 por su posición en el registro.).

${ }^{126}$ Véase supra, nota 70. Muchos de estos barcos reciben nombres distintos al genérico "nau", por lo que no podemos aventurar un cómputo exacto. Sin embargo, a medida que avanzabạ el mes de agosto se expedían órdenes de pago para los patrones de las naves fletadas al inicio de la armada, (ACA, C, reg. 1026, fols. 120 r. a 137 r. -asedio de Alguer, 1354, agosto, 25 septiembre, 25), lo que nos da una cifra próxima a las 20 que mencionaba el monarca.

${ }^{127}$ Además, recibió orden de enviar barcas a Granada y a Berberia para ordenar a los barcos de los súbditos del rey que acudiesen a Mallorca o a Cataluña antes de mediados de marzo de 1354 (todo ello en ACA $C$, reg. 1400 , fol. 26 r. Barcelona, 1354 , enero -datable alrededor del 20 por su posición en el registro-.). Confiscaciones y movilizaciones parecidas se registraron también en Cataluña, donde, por ejemplo, Pere Oliver, ciudadano de Barcelona, y el portero real García Valero recorrieron, en mayo de 1354, el litoral desde Barcelona a Sant Feliu de Guíxols para confiscar y llevar a Rosas todas las barcas que encontrasen, con el fin de usarlas para trasladar çaballos, hombres y vituallas a Cerdeña (ACA, RP, MR, 642, fol. 204 v. Barcelona, 1356, junio, 6).

${ }^{128}$ El término "nau" es genérico y designa cualquier embarcación redonda de cierto tamaño y propulsión vélica, mientras que el de "coca" es más específico, e identifica el uso de la vela cuadra. Como síntesis de las tipologías navales usadas a mediados del siglo XIV véanse obras como Rolf EBERENZ, Schiffe an den Küsten der Pyrenäenhalbinsel. Eine kulturgeschichtliche Untersuchung zur Schiffstypologie und-terminologie in den iberoromanischen Sprachen bis 1600 , Berna, Herbert Lang, 1975; N. COLL, Arcadi GARCIA SANZ, Galeres mercants catalanes dels segles XIV i XV , Barcelona, Fundació Noguera, 1994; Rudy GERTWAGEN, Característiques de les embarcacions maritimes de la Mediterrania durant els segles XIII-XIV, en David ABULAFIA; Elisenda GUEDEA. Joan ALEMANY (eds.), Mediterraneum. L'esplendor de la Mediterrània medieval. S. XIII-XV, Barcelona, Institut Europeu del Mediterrània-Lundberg, 2004, pp. 543-561; Marcel PUJOL i HAMELINK, La tipología naval medieval en Cataluña (siglos VIII-XV): Las fuentes de información, "Revista de Historia Naval" 88 (2005), pp. 27-56; D. Coulon, Barcelone et le grand commerce, pp. 134-164. Algunas de las naves que viajaron a Cerdeña, por ejemplo,
} 
llevar todo tipo de material — caballos, vituallas y personal — en función del número de cubiertas que tenían y de su tonelaje ${ }^{129}$. Eran barcos de gran capacidad y desplazamiento para los estándares de la época, que acostumbraban a llevar un solo mástil y velas cuadras como única propulsión. Estos barcos, que en esos momentos empezaban a experimentar una creciente tendencia a aumentar su tamaño y transformar su sistema de propulsión y gobierno ${ }^{130}$, diferían enormemente en sus tipologías y sistemas constructivos. El hecho de que en buena medida fuesen de propiedad privada - por lo tanto destinados ante todo a la actividad mercantil — ${ }^{31}$ dificulta su localización en las fuentes emanadas de los poderes públicos, mientras que en las de carácter privado las naves son difíciles de localizar, pues solían identificarse por el nombre de patrones y armadores, que variaban constantemente.

En segundo lugar, hay que tener en cuenta los grandes barcos de remos, de la familia de la galera, aparejados igualmente con remos y velas latinas pero con una capacidad de carga superior a la habitual de ésta. Dentro de este tipo, en la armada de 1354 se documentan pánfilos, taridas y ujieres. Los dos primeros tipos acostumbraban a ser de propiedad privada y fletados por la armada, de modo parecido al descrito más arriba ${ }^{132}$. Los ujieres, en cambio, formaban parte de la flota de combate, pero su capacidad de carga y su configuración interna les permitían desempeñar labores de transporte ${ }^{133}$. Si bien los ujieres podían llevar todo tipo de mercancías, destaca su capacidad de llevar caballos. Estos no sólo viajaban en habitáculos especiales, sino que, además, mediante una rampa, se podían desembarcar por la característica puerta que

recibieron el nombre de "naus castellanes", (AHCB, Consell de Cent, Ordinacions originals XVI-2, fol. 1 r. Barcelona, 1354, enero, 17.); para su diferencia constructiva, véase M. PUJOL, Els vaixells tinclats a la Catalunya medieval, en Actes del ler Congrès d'Història Marítima de Catalunya. Museu maritim de Barcelona 13, 14 i 15 de novembre de 2002. Barcelona, Consorci de les Drassanes Reials de Barcelona-Museo Marítimo de Barcelona, 2004, recurso electrónico, no paginado.

${ }^{129}$ Estos son los criterios de clasificación de los barcos para la campaña, ordenados por el rey al gobernador de Mallorca Gilabert de Centelles (ACA, C, reg. 1400, fol. 26 r. Barcelona, 1354, enero -datable alrededor del 20 por su posición en el registro).

${ }^{130}$ Frederic C. LANE, Technology and Productivity in seaborne transportation, en Antonio VANNINI MARX (ed.) Trasporti e sviluppo economico, secoli XIII-XVIII. Atti della Quinta Settimana di Studio, Istituto Internazionale di Storia Economica "F. Datini" Prato, 1973, Florencia, Le Monnier, 1986, pp. 233-244; A. RIERA, La construcció naval a Catalunya a les vespres dels grans descobriments geogràfics (1350-1450), "Revista d'Història Medieval" 3 (1992), pp. 55-78.

${ }^{131}$ Cabe señalar, sin embargo, que para la armada de 1354 se construyó en la atarazana regia de Barcelona la nave Sant Joan, cuya cuenta de gastos de su construcción se conserva en ACA, RP. MR, vol. 2284 .

${ }^{132}$ Por ejemplo, se registra la audición de las cuentas de Bartomeu de Vilafranca, ciudadano de Mallorca, por el flete de su pánfilo de 800 salmạs por Francesc Desportell y Jaume Negre, procuradores reales de Mallorca, para avituallar el ejérçito, a 10 sueldos de Barcelona por salma (ACA, RP, MR, 642, fol. 215 r. Barcelona, 1356, junio, 25).

${ }^{133}$ Por ello, pese a que en términos generales los ujieres pertenecían a la flota de combate, esta afirmación no siempre se cumplía. Hay que recordar que al gobernador Gilabert de Centelles, cuando se le ordenó retener los barcos en Mallorca, se le mandaba retener taridas, pánfilos y ujieres extranjeros en la isla (ACA, C, reg. 1400, fol. 26 r. Barcelona, 1354, enero -datable alrededor del 20 por su posición en el registro-). 
daba nombre a la embarcación ${ }^{134}$. En la armada aquí estudiada los ujieres no realizaron todo el transporte de caballos ${ }^{135}$; sin embargo, sí debían aprovechar su polivalencia y menor dependencia del viento para agilizar el transporte y dar, gracias a sus capacidades de buque de guerra, un valor añadido de seguridad defensiva a la carga.

Por fin, hay que tener en cuenta la presencia de numerosas barcas, leños y otras embarcaciones menores, que combinaban velas y remos y, gracias a su velocidad, a su versatilidad y capacidad de maniobra y al bajo coste de su armamento, se utilizaban básicamente para transportar personas y mensajes de todo tipo. Sin duda podían, igualmente, llevar carga ${ }^{136}$, pero, obviamente, no se optimitzaba tanto su puesta en marcha, pues su margen de beneficios o su ventaja no se hallaban en su baja ratio hombre/carga sino en la velocidad. Estos barcos menores solían ser de propiedad privada y fletados ad hoc, pese a que la armada armó algunos para tenerlos disponibles y cubrir ciertas necesidades inmediatas sin tener que depender de otras instancias ${ }^{137}$.

El transporte realizado por los barcos relacionados con la armada unía los reinos cismarinos con Cerdeña, llevando una serie de cargas muy específicas. Los déficits materiales del ejército que asediaba Alguer eran, básicamente, relativos a provisiones y refuerzos, mientras que, a un tiempo, la complicada logística necesaria para avituallarlo exigía una comunicación, tanto oral como escrita, constante entre el rey, los consejos reales, y el lugarteniente general.

En primer lugar, debido al enorme número de tropas que asediaban Alguer y al desgaste de los territorios que rodeaban la ciudad, el ejército necesitaba vituallas. Esta fue, como ya se ha dicho, una de las máximas prioridades de los consejos, y continuamente se coordinaron movimientos de suministros alimentarios desde todos los puntos de los reinos cismarinos, uniendo los lotes procedentes de distintos lugares de origen para enviarlos desde los puertos de embarque ${ }^{138}$. La documentación suele hablar de vitualles como

\footnotetext{
${ }^{134}$ Para el transporte de caballos y los barcos especializados, véase J. PRYOR, The transportation of horses by sea during the era of the crusades: Eight century to 1285 A. D., "The mariner's mirror" 68 (1982), pp. 9-27 y 103-125, e igualmente IDEM, The naval arquitecture of crusader transport ships: a reconstruction of some archetypes for round-hulled sailing ships, "The mariner's mirror" 70 (1984), pp. 171-219, 275-292 y 363-386.

${ }^{135}$ Resulta impensable en un ejército de 1000 caballos armados y 500 a la jineta, entendiendo los caballos armados y alforrados como unidades militares que incluían varias personas y más de una montura (M.T. FERRER, La organización militar, pp. 169-173). Con una capacidad de carga cercana a los 20 caballos por ujier queda claro que el transporte de monturas no dependia únicamente de los ujieres (ACA, C, reg. 1398, fol. 19 v. Barcelona, 1353, diciembre, 27; la carta habla, sin embargo, de XX cavalls e no pus, cosa que implica que 20 es un número superable).

${ }^{136}$ De hecho, los barcos de este tipo movilizados, como se ha dicho, por la fuerza en Mallorca y en Cataluña lievaron todo tipo de cargas en la medida en que lo permitía su capacidad.

${ }^{137}$ AHPB, Pere Martí, Llibre d'àpoques de l'armada contra els genovesos, 17/29, fol. 28v. Barcelona, 1354, abril, 24.

${ }^{138}$ Se documentan, por ejemplo, compras en Navarra, sobre las que destacan los capítols u órdenes dadas a Francesc Llancer -también llamado Francesc Julià-, ciudadano de Barcelona, y miembro de la casa del infante Pedro (A. BEAUCHAMP, Gouverner la Couronne, p. 203) sobre este particular (ACA, C, reg. 1606, fol. 93 v. Barcelona, 1354, octubre, datable entre el 6 y el 11 , por su posición en el registro) encargándole comprar caballos, tan buenos como pudiera encontrar, para enviárselos al rey en la primera nave disponible; igualmente, se ha conservado la audición de cuentas de este viaje (ACA. RP, MR, vol. 642, fol. 198 r. Barcelona, 1354, abril, 24).
} 
término genérico. Si bien en ocasiones especifica el tipo concreto de vitualla transportada, lo cierto es que, desde el punto de vista del transporte, éstas se tratan como un mismo tipo de carga, por el hecho de que se trataría de productos inertes susceptibles de ser estibados en los barcos sin excesivas dificultades ni adaptaciones especiales.

Después, el segundo artículo que la documentación trata como una categoría aparte son los caballos. La gran escasez de caballos sufrida por el ejército que combatía en Cerdeña obligaba incluso a extender la logística asociada a ellos, consiguiéndolos fuera de los reinos de la Corona de Aragón y transportándolos por tierra hasta un puerto de embarque. Parece obvio que su transporte debía de realizarse en barcos de cierta capacidad; como ya se ha comentado, los ujieres permitían un transporte óptimo de los animales, pero todo tipo de buques podía transportarlos, siempre que se habilitase su interior para llevar las bestias mediante reformas, en función del número de caballos previstos $^{139}$.

En tercer lugar, la documentación nos habla de transporte de personas. A partir del primer movimiento conjunto desde Rosas a Alguer, la documentación nos muestra que la petición $\mathrm{y}$, siempre en menor medida, el envío de refuerzos - con especial importancia de los ballesteros - son constantes. Una vez más, si en el primer viaje las tropas embarcaron en todo tipo de barcos disponibles - que no necesitaban, obviamente, ningún tipo de adaptación especial para transportar personas-, a partir de entonces también se concentraron en grupos numerosos para ser transportados en barcos de gran capacidad, con o sin otras cargas ${ }^{140}$.

Conviene, por último, recordar que todo viaje a Cerdeña tenía, obviamente, un trayecto inverso hacia los reinos metropolitanos de la Corona de Aragón. Cocas y naves de la armada, por ejemplo, hacían viajes constantes para volver a Cataluña o Valencia a cargar ${ }^{141}$, pero no parece lógico que pudiesen llevar demasiados artículos comerciales — salvo, tal vez, algun flete de Sassari o cautivos sardos_- procedentes de una zona de guerra con la ratio

\footnotetext{
${ }^{139}$ Aun en un barco apropiado para transportar bestias, como el caso de un ujier, debían habilitarse las estanques para adaptarlo a llevar 20 caballos (ACA, C, reg. 1398, fol. $19 \mathrm{v}$. Barcelona, 1353, diciembre, 27).

${ }^{140} \mathrm{Las}$ condiciones de transporte debían de ser, para la tropa, considerablemente duras, debido a la necesidad de optimitzar espacio. Se sabe que era posible cargar 500 peones en 3 ujieres (ACA, C, reg. 1398, fol. 19 v.). Contando con el hecho de que el ujier era un barco de la familia de la galera -que, por lo tanto, debía llevar una dotación de remeros- la dotación y el pasaje debían de tener serios problemas de espacio, en un viaje en absoluto exento de complicaciones. Se documenta sin embargo que, obviamente, las condiciones de vida a bordo reflejaban la posición social de quien viajaba; nobles y miembros de la familia real habilitaban camarotes en los barcos (AHPB, Pere Martí, Llibre d'ápoques de l'armada contra els genovesos, fol. $32 \mathrm{v}$. Barcelona, 1354, mayo, 18). Cabe destacar aquí el episodio de la galera real, patroneada por Antoni Amat, que tuvo problemas de navegabilidad por culpa de la sobrecarga producida por los equipajes del rey y de la infanta de Mallorca, y tuvo que descargar parte de las mercancias que llevaba; A. CASTELLACCIO, Note e documenti sul viaggio di Pietro IV in Sardegna (1354-1355), en IDEM, Aspetti di storia italo-catalana, Cagliari, Istituto del C.N.R. per i Rapporti Italo-Iberici, 1983 , pp. 103-183.

${ }^{141}$ Es obvio que la única manera de amortizar los barcos fletados por la armada era procurar que viajasen llenos. Gobernar un barco con la carga incompleta no es sólo antieconómico sino también perjucicial para su navegabilidad, pues el centro de gravedad de la nave -pensada y diseñada para ir cargada- se alza, con lo que ésta pierde estabilidad.
} 
producción/consumo desequilibrada por numerosos combatientes. Lo más probable es que llevasen, principalmente, la única cosa que le sobraba al ejercito: enfermos, heridos y gente que, cumplido su periodo de servicio, volvía a su lugar de origen. Se documenta el retorno de varios nobles por enfermedad ${ }^{142}$, pero debemos pensar que había un flujo constante de hombres que causaron baja hacia los reinos cismarinos, suficiente gente de guerra como para llenar varios hospitales ${ }^{143}$.

En otro plano de actuación, las comunicaciones y la información fueron básicos para coordinar esfuerzos y transmitir órdenes en el complicado organigrama de la armada, con una estructura tan compleja y fragmentada en una extensa área geográfica y dividida por el mar. A un tiempo, el conocimiento anticipado de los planes enemigos ha sido siempre el primer paso para actuar correctamente ante él, por lo que los mandos necesitaban informarse no sólo de la situación propia sino también de lo que sucedía en tierres enemigas.

Las cartas que se intercambiaban los consejos reales, el rey y su lugarteniente general iban prioritariamente, com es lógico, en cualquier barco que se armase para cargar los productos necesarios para la armada real. Sin embargo, éstos eran prioritariamente barcos de carga, cuyo movimiento estaba condicionado por la producción, reunión y disponibilidad de la carga y el pasaje que, siendo de tan distinta procedencia, podían pasar un cierto tiempo en los puertos de embarque esperando que se completase el lote. Cuando un mensaje era de carácter demasiado urgente y no podía esperar a adaptarse al ritmo de las vituallas, solían armarse barcos pequeños — normalmente barcas o leños - para llevar mensajeros ${ }^{144}$. Cabe pensar que el sistema de pequeños barcos armados para llevar correo era considerablemente inseguro, por lo que con frecuencia se tomaban todo tipo de precauciones para asegurar la correcta transmisión de la información ${ }^{145}$; la ventaja de maniobrabilidad y velocidad de leños y barcas era inefectiva ante las galeras enemigas, frente a las que en combate se hallaban indefensos. Debe tenerse en cuenta, asociado a la transmisión de órdenes, el papel del espionaje y la información en la toma de decisiones de los mandos de una operación militar. Las referencias son escasas, pues es lógico pensar que en estos casos era necesario, en la medida de lo posible, evitar la palabra escrita

\footnotetext{
${ }^{142}$ PedRo IV, Crónica, V-36. Por su posición social y su poder adquisitivo cabe pensar que no debían de tener problemas para hallar un pasaje.

${ }^{143}$ Así nos dice un libro de cuentas de la Majordomia de la Pia Almoina de la Catedral de Barcelona (ACB, Pia Almoina, Majordomia, B2C, fols. 207 v. y 208 r; debo y agradezco esta referencia a Adam Franklin). La corte incluía los enfermos evacuados entre las cargas de los distintos fletes, como se ve en la orden, enviada al Consejo Real de Barcelona, de asistir a los enfermos pobres que llegaban en el leño de Bernat Castelló (ACA, $C$, reg. 1026, fol. $103 \mathrm{r}$. Asedio de Alguer, 1354, julio, 23.). Es comprensible, pues los enfermos no sólo eran focos de malaria y otrăs enfermedades, sino también bocas inútiles que, además, precisaban de cuidados y comidas especiales (PEDRO IV, Crónica, V-36).

${ }^{144}$ Sirva de ejemplo la barca de entre 24 y 30 remos que Pedro IV mandó armar a Gilabert de Centelles, gobernador de Mallorca, para Ilevar cartas a Artal de Pallars, capitán de Cagliari (ACA, C, reg. 1400, fol. 17 v. Barcelona, 1354, enero, 16.).

${ }^{145}$ Guillem Morro transcribe varios documentos que hablan de la presa de barcos menores, destinados al correo, por parte de galeras genovesas; véase supra, nota 36. En la mencionada orden enviada a Gilabert de Centelles para armar una barca (véase supra, nota 145) el rey le insistía en el hecho de que la barca debía detenerse sólo en Cagliari o en Iglesias -zonas seguras en manos catalanas- y refugiarse en tierra en caso de que divisase barcos enemigos.
} 
que pudiese ser interceptada ${ }^{146}$. La red de contactos de la Corona y de las personas vinculadas a sus armadas - muchas de ellas pertenecientes a la burguesía mercantil - se ponía en movimiento, superponiéndose a los negocios y a la diplomacia, alcanzando todo el Mediterráneo occidental ${ }^{147}$.

De nuevo, sin embargo, la planificación y las capacidades económicas de la armada sufrieron graves problemas para adaptarse a la situación planteada por el bloqueo del avance en el asedio de Alguer. Con la creciente amenaza de los ataques genoveses en el mar y la insolvencia de los pagadores de la armada, el flete resultaba menos atractivo, tanto en el plano económico como en el político $^{148}$; pese a que muchos patrones renovaron sus fletes al servicio de la armada a partir de agosto, la escasez de dinero en el real impedía mantener totalmente el ritmo de barcos movilizados ${ }^{149}$. Por otra parte, en el mismo proceso descrito para el alza de precio de las vituallas se incluía la atractiva opción de navegar con mercancía propia, revendiéndola a precios mucho más rentables que los que podía pagar la armada por un espacio de carga equivalente. Así, el fracaso del plan operacional puso a prueba las capacidades de la armada para abastecer a un ejército que consumía sin apenas vivir sobre el terreno. Alcanzado el techo de las capacidades públicas para ofrecer suministros a la armada, la iniciativa privada cubrió, también en el aspecto del transporte, las necesidades de la expedición, incentivada por las licencias regias y atraída por la prespectiva de ganancia rápida.

${ }^{146}$ Las referencias tienden a aparecer cuando algún miembro del aparato logístico o de mando de la armada contacta con otro y hace referencia a un espía (ACA, $C$, reg. 1606, fol. $113 \mathrm{r}$. Lérida, 1354, diciembre, 21.).

${ }^{147}$ Por ejemplo, se documenta, para Provenza y otras localizaciones, el envío o la presencia de espías, que dieron informaciones vitales sobre la puesta en marcha de las galeras genovesas que habían de castigar las comunicaciones entre la armada y los reinos cismarinos de Pedro el Ceremonioso. El envío de espías a territorios enemigos fue también una de las prioridades del consejo real de Barcelona al inicio de la armada de 1354 (AHCB, Consell de Cent, Ordinacions originals XVI-2, fol. $1 \mathrm{r}$. Barcelona, 1354, enero, 17.), y las referencias apuntan al contacto con mercaderes catalanes que, directamente o a través de sus factores, recababan información y la hacían llegar a los oficiales regios; véase supra, nota 31.

${ }^{148}$ La documentación regia registra, a partir de agosto de 1354, una constante expedición de letras debitorias, en prueba de lo que se intuye como préstamos forzosos para dar liquidez inmediata a la armada. Por ejemplo, se entregó a Bernat Serra, patrón de nave de Mallorca, una carta debitoria por valor de 350 florines, 80 escudos de Francia y 600 sueldos de Barcelona, cantidades que pasaron a manos de Pere de Màrgens, encargado de la tesorería en la isla, y que el mercader debía recibir, en un mes, en la mesa de Jaume Desvilar, en Barcelona (ACA, $C$, reg. 1026, fol. 138 r. Asedio de Alguer, 1354, septiembre, 25.). Se analiza el movimiento de préstamos de este tipo por parte del personal sanitario, particularmente el que se adscribía a la casa del rey, en L. CIFUENTES, Medecina i guerra, pp. 403-412. Pese a que esta situación podría parecer poco atractiva para los mercaderes, patrones y particulares afectados, conviene no olvidar que la monarquía podia pagar los favores con rentas o con todo tipo de concesiones extraeconómicas; véase L. CIFUENTES, Medecina i guerra, p. 369-377, así como M. ORSI, Les dotacions, pp. $57-58$.

${ }^{149}$ La monarquía se veía incapaz de pagar todos los barcos fletados, lo que condujo a desmovilizar algunos y ofrecerles la posibilidad de seguir transportando vituallas por su cuenta, dándoles libertad para venderlas al precio que desearan; es el caso de dos leños desmovilizados por el rey en agosto de 1354. (ACA, C, reg. 1026, fol. 117 r. Asedio de Alguer. Datable entre 20 y 26 de agosto por su posición en el registro). 


\section{CONCLUSIONES}

A lo largo del presente estudio se ha tratado de esbozar, a grandes rasgos, el perfil básico, el esqueleto sobre el cual se asentó el desarrollo de la campaña dirigida por Pedro el Ceremonioso en Cerdeña, en el verano de 1354. Esta fue, probablemente, la armada más potente que jamás habían movilizado los reyes de Aragón hasta la fecha, lo cual nos plantea una serie de problemas y nos lleva a dar respuesta a algunos de ellos, dejando otros en hipótesis, líneas abiertas de investigación pendientes de recorrer. Las líneas básicas que se han trazado siguen, limitadas por la documentación a nuestro alcance, por la trayectoria marcada por el marco geográfico general y el contexto político del momento, por la planificación y ejecución de una operación militar y por los medios logísticos necesarios tanto para sostenerla como, debe subrayarse este aspecto, para adaptarla a las cambiantes circunstancias de la guerra.

En primer lugar, se ha visto cómo las ecuaciones políticas y estratégicas de la isla de Cerdeña cambiaban radicalmente con la rebelión del juez de Arborea. Ahondando en las complicadas relaciones de poderes existentes en la isla, se podría considerar que Mariano IV, ante una situación de bloqueo de sus relaciones con el rey y sus oficiales, atraído por las ofertas de alianza de Génova y Milán, decidió cambiar el alineamiento político de sus antepasados. Desde 1353 todas las capacidades militares catalanoaragonesas en Cerdeña se vieron comprometidas, por lo que la armada del año siguiente tuvo que responder a un nuevo modelo organizativo y a un plan diferente, que se adaptaran a las nuevas circunstancias.

Observando la armada desde el punto de vista operacional, queda claro que, por varios motivos, las intenciones de sus mandos pasaban por asegurar rápidamente las comunicaciones entre las fuerzas regias del norte de la isla y los reinos cismarinos, para después avanzar sobre Mariano de Arborea con el ejército de maniobra fresco y aprovisionado. Este plan de operaciones exigía necesariamente tomar Alguer en pocos días; si bien no puede decirse que no fuese factible, las dificultades de tomar una plaza fuerte al asalto eran, en pleno siglo XIV, considerables. Con un esfuerzo mínimo de hombres y recursos, la guarnición de la ciudad mantuvo la plaza durante cinco largos meses, convirtiendo la campaña de maniobra planeada por Pedro IV en un largo sitio, que desgastó el ejército regio hasta el punto de llevarlo a una desventajosa negociación.

La organización logística adscrita a la armada no estaba preparada para una campaña de este tipo. La flota de transporte, apoyada por la movilización forzosa de numerosos barcos, estaba pensada para desembarcar el ejército en el primer momento y para sostener una línea de suministro, que debía complementar las provisiones conseguidas en Alguer y en territorio enemigo. La imposibilidad de acceder a los mencionados stocks enemigos hizo que sobre la flota recayese un cometido difícil, pues debió mover un volumen de material mayor del previsto, mientras los genoveses golpeaban sus rutas y numerosos barcos particulares dejaban de apoyar a la armada para navegar en sus propias 
empresas comerciales. El resultado es bien conocido: el desabastecimiento del ejército sitiador derivó en escasez y enfermedades, que se sumaron a las bajas producidas en combate para dejar el imponente ejército catalanoaragonés al borde de la extenuación.

Cabría ahora, pues, llegar a la relación entre los tres factores analizados más arriba: los condicionantes, los planes y el desarrollo operacional, la logística asociada a ellos, en definitiva, algunas de las principales claves del éxito o del fracaso de una campaña militar. En el estudio de caso presentado aquí parece obvio que los planes del rey de Aragón, pensados sobre una base material reducida y en circunstancias geoestratégicas adversas, asumieron algunos riesgos confiando en ganar tiempo y ahorrar en el consumo de sus escasos recursos. Su incapacidad de mantener esta armada operativa en caso de adversidad indica no sólo lo arriesgado del planteamiento, sino también, en buena medida, el techo de las capacidades de la señoría del rey de Aragón. Este límite estaba marcado, en el caso de la guerra de Cerdeña, no tanto por la falta de recursos de los reinos - entendidos en un sentido amplio, humano como económico - como por la incapacidad del monarca para destinarlos a guerrear en la isla, hostil a las iniciativas regias, de forma abundante o continuada.

El estudio exhaustivo de las las expediciones catalanoaragonesas a Cerdeña está todavía pendiente, pero acaso sea necesario tener en cuenta el caso aquí estudiado en la construcción de un modelo interpretativo, pues los rasgos que se han intentado describir respondían a dinámicas y problemas concretos que marcaron - esto es, imposibilitaron - la sujeción de Cerdeña a las armas de Pedro el Ceremonioso.

Después del breve periodo de 1355-1356, durante el cual todas las partes combatieron mediante contingentes más pequeños y planes menos ambiciosos, la Guerra de los Dos Pedros desplazó las prioridades militares del Ceremonioso a sus reinos cismarinos, renunciando casi por completo a tratar de recuperar la iniciativa en Cerdeña. Tras el paréntesis de la guerra con Castilla, nuevas armadas trataron de asestar, sin éxito, un golpe definitivo al juez de Arborea; todas toparon con dificultades operativas y logísticas, de índole similar a las descritas en este trabajo.

En ocasiones se intentó superarlas con planes muy agresivos que, como en el caso del desastre de 1368, se cobraron su precio, dejando la isla casi sin presencia catalana hasta la centuria siguiente. Se hicieron también planes para enviar a la isla varias armadas posteriores. Ninguna de ellas se materializó, por causas que aún no se conocen con claridad; parece claro, sin embargo, que las dificultades logísticas y económicas de estas empresas debieron de ser parte importante del problema ${ }^{150}$. Estas dinámicas, aún insuficientemente conocidas, nos dan una idea de la línea de actuación seguida por Pedro el Ceremonioso en el Regnum Sardiniae a partir de la expedición regia de 1354: disminución de los esfuerzos invertidos en la isla, cesión de la iniciativa a los enemigos del rey y, en los raros casos de campañas ofensivas, delegación de funciones e insuficiente

\footnotetext{
${ }^{150}$ Véase M. SÁNCHEZ, Las cortes de Cataluña, pp. 282-294.
} 
apoyo de las cortes y asambleas estamentales de los reinos cismarinos. Como ya se ha apuntado, la experiencia de la armada e viatge del rey Pedro estuvo marcada por unas circunstancias negativas que, puesto que se mantuvieron intactas durante décadas, determinaron la historia militar, económica y política del reino sardo - y de la presencia catalana en él— hasta la centuria siguiente.

Si la expedición regia aquí estudiada puede contribuir a la comprensión de las realidades politicomilitares de la presencia catalanoaragonesa en Cerdeña, su rastro documental, amplísimo al estar dirigida por el propio rey, también aporta detalles que permiten enlazarla con su contexto socioeconómico. Los costes humanos de la guerra, su impacto económico, el aumento del tamaño de ejércitos y flotas, así como el desarrollo de sistemas administrativos y fiscales para su mantenimiento y gestión, son procesos de larga duración que afectaron, como se ha apuntado, a todo el occidente bajomedieval y a la señoría de los reyes de Aragón. Los detalles señalados en el presente trabajo dan algunas indicaciones: las bajas de los combatientes en el sitio de Alguer, la distorsión o readaptación del transporte y del comercio y los daños a la población no combatiente son evidencias intrínsecas a la guerra, ampliamente documentadas en estas páginas. Otros aspectos de la campaña de 1354 — principalmente los que se relacionan con la fiscalidad - han sido profusamente estudiados, colocando la guerra entre los primeros motores de las transformaciones sociopolíticas bajomedievales. Este estudio, centrado en aspectos concretos de una campaña determinada, puede aportar detalles y evidencias útiles para configurar, desde el estudio de caso, el perfil de esquemas y modelos interpretativos de mayor alcance, tanto temático como cronológico, para la comprensión de la guerra y de la sociedad que la produce, aplicables a la Corona de Aragón y susceptibles de entrelazarse con la historia del occidente bajomedieval.

Se puede concluir, una vez más, que la expansión mediterránea de la Corona de Aragón, por sus especificidades históricas y por las fuentes que nos han llegado, sigue siendo un laboratorio de primer orden para estudiar la historia militar del occidente medieval, sus implicaciones socioeconómicas y sus relaciones políticas. Y también merece la pena subrayar que, pese a la indudable tradición de meritorios estudios, tanto clásicos como recientes, es un camino por recorrer.

Fecha de recepción del artículo: mayo 2008.

Fecha de aceptación y versión final: septiembre 2008. 


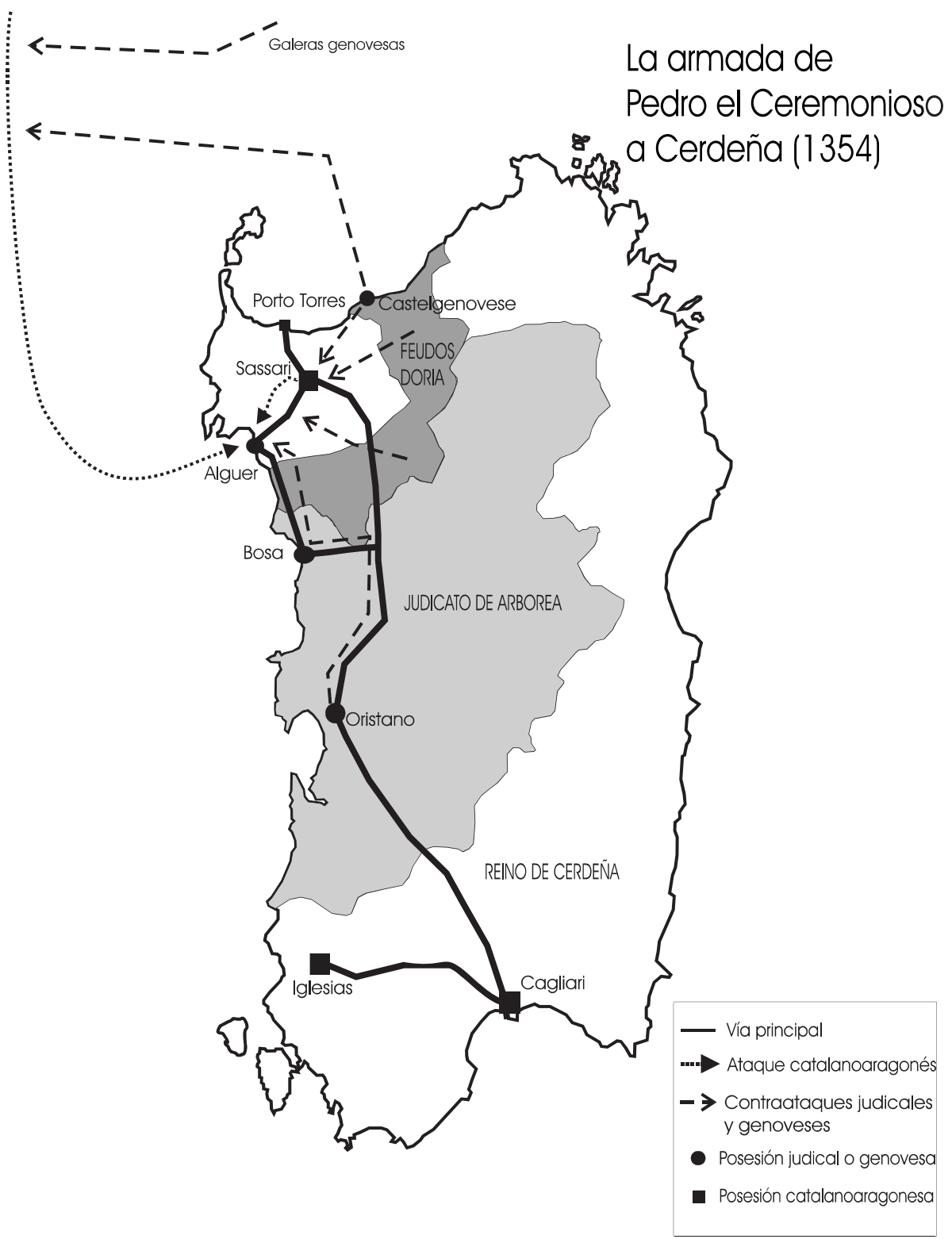

